\title{
A Review of Contemporary Work on the Ethics of Ambient Assisted Living Technologies for People with Dementia*
}

\author{
Peter Novitzky Alan F. Smeaton Cynthia Chen Kate Irving \\ Tim Jacquemard Fiachra O'Brolcháin Dónal O'Mathúna \\ Bert Gordijn
}

\begin{abstract}
Ambient assisted living (AAL) technologies can provide assistance and support to persons with dementia. They might allow them the possibility of living at home for longer whilst maintaining their comfort and security as well as offering a way towards reducing the huge economic and personal costs forecast as the incidence of dementia increases worldwide over coming decades. However, the development, introduction and use of AAL technologies also trigger serious ethical issues. This paper is a systematic literature review of the on-going scholarly debate about these issues. More specifically, we look at the ethical issues involved in research and development (R\&D), clinical experimentation, and clinical application of AAL technologies for people with dementia and related stakeholders. In the discussion we focus on: 1) the value of the goals of AAL technologies, 2) the special vulnerability of persons with dementia in their private homes, 3) the complex question of informed consent for the usage of AAL technologies.
\end{abstract}

Keywords: dementia, ethics, ambient assisted living, ambient intelligence, ambient technology, informed consent

\section{Introduction}

\subsection{Ageing of the World Population}

Due to increased life expectancy and a falling birth rate, the age distribution in developed countries is gradually shifting towards older populations. Even though the population on our planet is still increasing overall, the birth rate in some countries has decreased to such a level that it has become impossible for them to maintain the sizes of their populations.

\footnotetext{
*The final publication is available at Springer via http://dx.doi.org/10.1007/ s11948-014-9552-x
} 
One of the first nations confronted with this trend was Japan. Its current demographics already demonstrate a high proportion of over-60 year olds, a result of repeated baby booms after World War 2. In 1950, Japan's population pyramid was a standard slow growth (box) shape but by 2010, $23 \%$ of its population was older than 60 . Within the next 40 years, that percentage is predicted to almost double to $39 \%$ (Statistics Bureau, Japan, 2011).

Eurostat's population projections (2011) reveal that Europe is going through a similar process. Whilst in 1960, an average ratio of three young people to one elderly person existed, it is predicted that there will be more than two elderly people to one young person by 2060 . For most of the $20^{\text {th }}$ century, the country with the highest median age, at 36, was Sweden. This was surpassed in the 1990s by Italy. It is predicted that in the next 30 years, Germany will become oldest country in Europe, which will then be superseded by Latvia and Romania by the year 2040, at which time, Sweden will have one of the lowest median ages. The proportion of the 'oldest-old' elderly persons (aged over 80 ) in Europe's average population will be about $10 \%$ by 2060 , five- to ten-fold more than the $1-2 \%$ at the beginning of the $20^{\text {th }}$ century (Eurostat, 2011).

From the World Population Prospects of the United Nations figures, revised in 2006, it is obvious that almost none of the countries in the world will avoid the consequences of the ageing population, over the next 50 years. By 2050, all developed countries, together with Latin America, the Caribbean, and most of Asia including China, are expected to have a median age of around 40 years. Most African countries will still have a median age of 30 years by 2050 compared to 25 years at the moment (UN, 2006).

What all this evidence points to is an unavoidable, worldwide, increase in the age profile for humankind and therefore an increase in the prevalence of age-related diseases, including dementia. The ageing of the population necessitates better and more effective health care systems and technologies.

\subsection{Emergence of Ambient Assisted Living Technologies}

One of the most common co-morbidities of elderly people is dementia, which is diagnosed by a set of progressive symptoms such as aphasia (loss of language function), apraxia (loss of the ability to perform intentional movements), as well as agnosia (loss of the ability to recognise objects), and problems with abstract thinking and complex behaviour. The most common form of dementia is generally accepted to be Alzheimer's disease (AD). In the early stages, a person with dementia (PwD) needs memory support, help with regular daily activities and social contact. In the mild stage of the disease, special medication and medical care become necessary. Care and management continue and are progressively more intensive as the disease progresses until it reaches the most severe stages. One of the symptoms of AD is a tendency to wander from the home and at some point sleep eventually enters a phase shift with wakeful nights leading to night-time wandering, which is usually the precursor to institutionalization.

Care and management of PwDs are multi-faceted, and can include prevention, enablement and treatment once the disease presents. The prevalence of the disease and the heterogeneity of the age cohort affected means that there are a variety of needs that need to be recognised (Gaul and Ziefle, 2009; Grönvall and Kyng, 2012; Kaye, 
2010; Lynch et al., 2009; Mordini et al., 2009; Oppenauer et al., 2007; Remmers, 2010; Salces et al., 2006), which can often only be fulfilled at significant economic, personal, organisational, social and managerial costs (Mandell and Green, 2011).

Using the latest technology, ambient assisted living (AAL) technologies aim to provide PwDs with the means to actively live their daily lives, protect their dignity, feel safe, maintain their capacities, sustain their integration with their communities, and help their care-givers in monitoring and preventing avoidable complications in consecutive treatment. This is distinct from other uses of technology in, for example reminiscence therapy (Bermingham et al., 2013) where PwDs can receive external stimuli to trigger their memory recall and which, for a short period of time (duration the reminiscence therapy session and some short period afterwards) helps raise their quality of life. In addition to the main goal, i.e. of providing support for PwDs on a near full-time basis, AAL technologies aim to provide data that are necessary for effective care management and provide mobile support for care-givers at a more affordable cost than that at presently available. Despite the high hopes invested in AAL technologies, research is still ongoing and rollout is at an early stage. Although many research projects are underway worldwide, including projects like Easyline+ (Picking et al., 2012) and Dem@Care (McHugh et al., 2012), very few clinical trials have yet been completed and rolled out to a large population.

\subsection{Scope of Paper}

Responsible development of AAL technologies demands substantial analysis of the ethical issues, which might occur during R\&D, clinical trials or eventual clinical application (Emanuel, Wendler, and Grady, 2000; Emanuel, Wendler, Killen, et al., 2004). During these stages of development, various claims and interests emerge from different stakeholders. Therefore, the question we address in this paper is: what are the ethical issues involved in the stages of $\mathrm{R} \& \mathrm{D}$, clinical experimentation, and clinical application of AAL technologies for people with dementia and related stakeholders? We limit the scope of our investigation to this area and pose questions like how well known are these issues, and are there any accepted resolutions. We do this by carrying out a literature review and organizing and categorizing the information we have found, and in the next section we describe the methodology we have followed in carrying out this review.

\section{Methodology}

A literature review is the most commonly-used methodology to survey an area, especially an emergent area which has many stakeholders and for that reason that is the methodology we adopted. For our review, we used the following available medical, legal, sociological, engineering and computer science databases, which also cover the fields of philosophy and applied ethics: Web of Knowledge (containing: Web of Science, BIOSIS, MEDLINE, and Journal Citation Reports) ${ }^{1}$ with sources since 1945 , Springer-

\footnotetext{
${ }^{1}$ Accessible through: http://www . webofknowledge.com
} 
Link $^{2}$ with sources ranging from 1832 to the present, and the meta-database Scirus (Elsevier) $^{3}$, which contains twenty databases (including major scientific databases such as BMJ Group, IOP Publishing, MEDLINE/PubMed, Nature Publishing, Royal Society Publishing, SAGE Publishing, ScienceDirect, and Wiley-Blackwell), with sources since the year 1900. The searches were undertaken using a combination of terms in ten search phrases, listed in Table 1. The searches were adjusted according to the manuals of the particular databases and their filters (using wildcards, regular expressions, etc.), which varied slightly according to their required syntax.

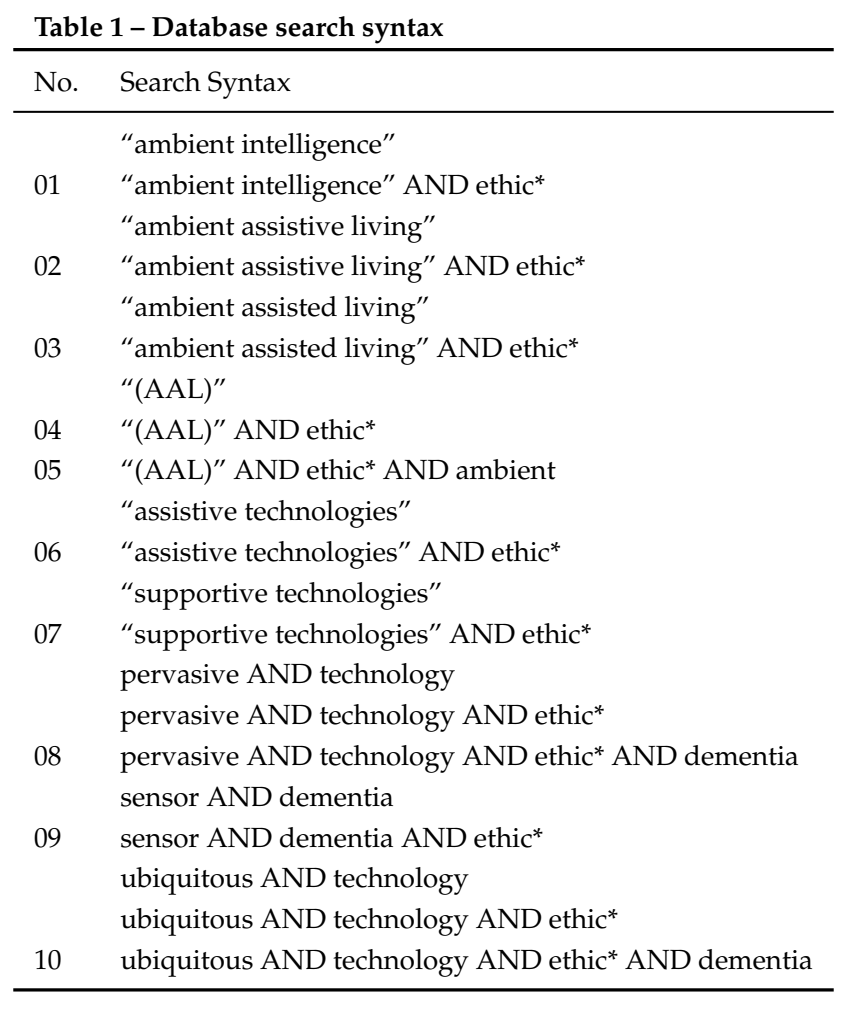

Table 1: Database search syntax

Ten searches ${ }^{4}$ of the three databases produced a total of 1,720 hits (including possible overlaps). These included a variety of sources such as articles in journals, literature reviews, abstracts and conference proceedings, chapters of books and edited volumes. Figure 1 shows the number of identified sources in each database and demonstrates a major increase in sources dealing with the ethics of AAL. The first article identified in the search was from 1965.

A more detailed diagram of the search results per database shows that the largest number of identified sources comes from SpringerLink, followed by Scirus, then Web of Knowledge (Figure 2).

\footnotetext{
${ }^{2}$ SpringerLink website: http: / / www . springerlink. com

${ }^{3}$ Scirus website: http: / / wWw. scirus.com

${ }^{4}$ In the meta-database Scirus (Elsevier), the search was refined to Abstracts, Articles, Books, Conferences, only PDF articles, with subject areas: Computer Science; Engineering, Energy and Technology; Law; Life Sciences; Medicine; Social and Behavioral Sciences; Sociology. When the individual search

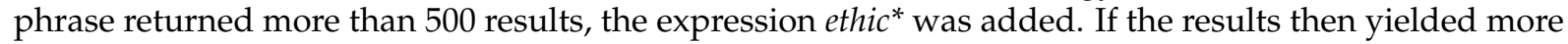
than 200 results, the additional word dementia was added, further specifying the search phrases and subject matter of the literature review. The search was restricted to the end of 2012 .
} 


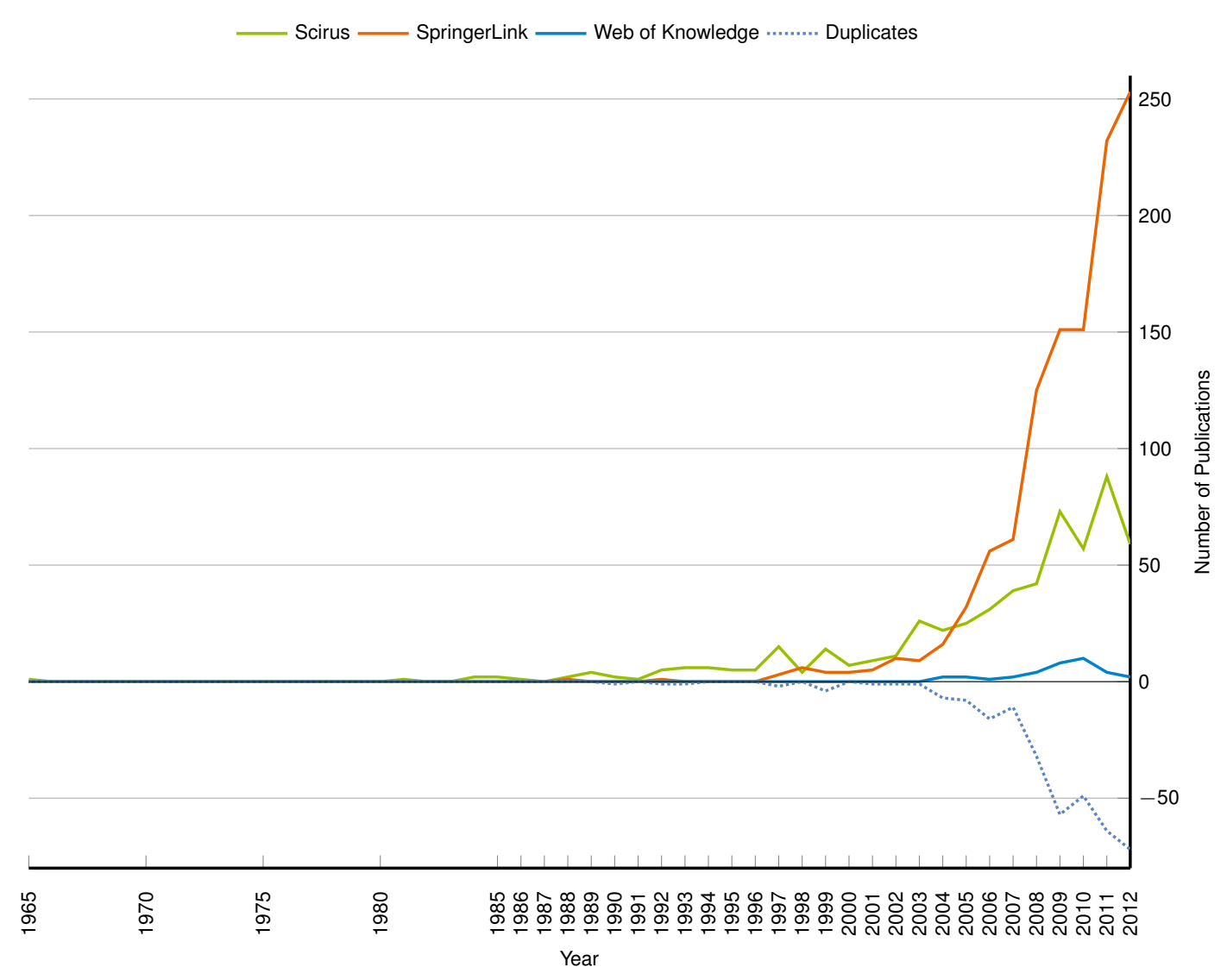

Figure 1: Overall timeline of the results

Following this initial trawl of the literature, the relevance of the sources was judged manually on the basis of title and abstract. Articles whose abstracts focused on very general and broad topics of technology and ethics, and not directly connected to the ethical issues of AAL technologies, smart homes, sensor technologies, elderly persons, persons with dementia, etc. were excluded. An article was deemed relevant if it appeared to focus on ethical issues relating to new (ambient-, sensor-, smart-) technologies for the elderly or PwD. Due to the large number of results and for reasons of practicality, sources without available abstracts were excluded.

This initial analysis of the search results yielded 350 relevant sources. The majority (341) of the relevant articles were in English, 6 in German, 2 in French, and one in Norwegian. The number of duplicates within the group of relevant articles was 177, resulting in 173 unique relevant sources from the 10 searches. Thirteen other sources were added, which were not present in the chosen databases; they were either listed in the references of relevant articles, or they were found during the unsystematic search for authors well-known in the field of AAL technologies, and which were seen as clearly relevant for this review. However, they were not included in the 173 results of the original 10 searches. As a result, we had 186 relevant sources. From reading and systematically classifying the content of these articles, a clear trend can be observed in the increasing number of relevant articles addressing the ethics of AAL technologies, over time (Figure 3). 


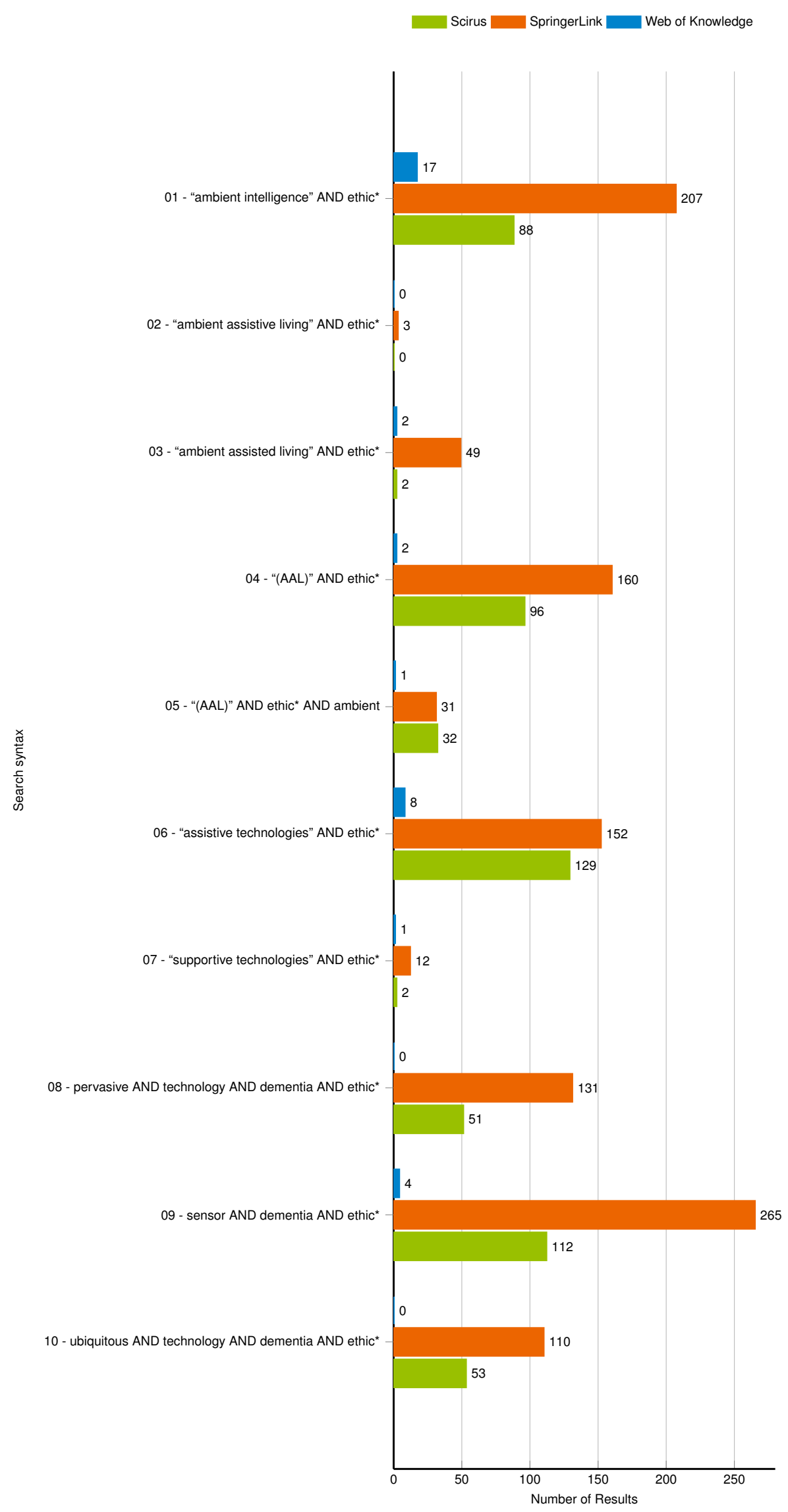

Figure 2: Search results in the individual databases 


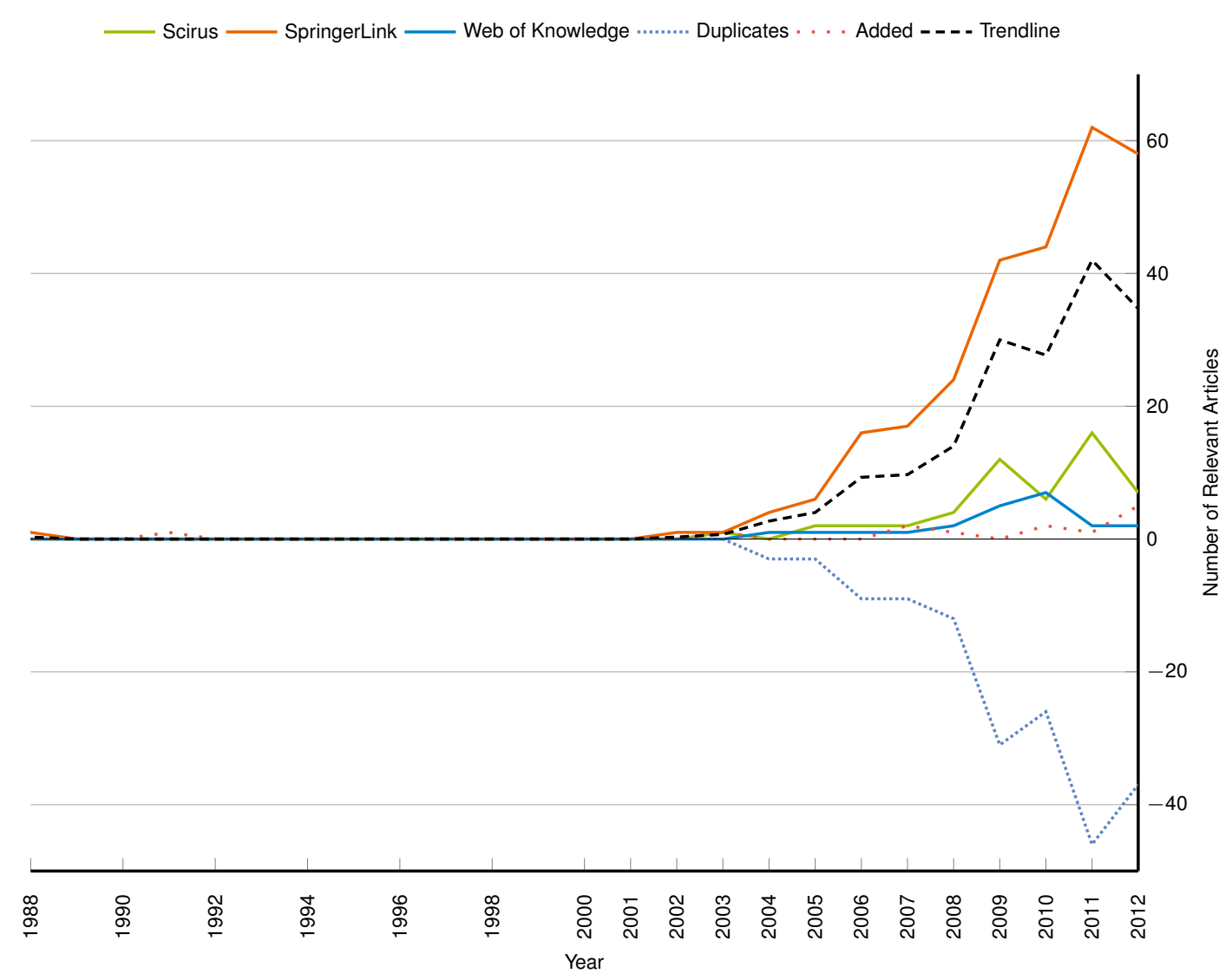

Figure 3: Timeline of relevant articles

\subsection{Terminology}

According to the literature reviewed, the term Digital Assistive Technologies (DAT) can be used for any item that assists persons with their disabilities (Francis et al., 2009). DAT are a category of ambient intelligence (AmI), which involves intelligent computing, with elements of pervasiveness and ubiquity. The term 'intelligence' refers to the adaptability of such a system to the presence of human beings and to the needs of the user. The term 'pervasive' refers (in the literature) to information and communication technologies (ICT) that are available "everywhere, for everyone, at all times" (Duquenoy and Whitehouse, 2006, p. 293). 'Ubiquitous' - the term introduced originally by Weiser (Portet et al., 2011) - covers the disappearance-into-background of the technology in an invisible, interconnected and non-intrusive way (Duquenoy and Whitehouse, 2006; Duquenoy, 2004). This pervasive, ubiquitous and non-intrusive nature is often also called 'calm computing' (Spiekermann and Pallas, 2006; Wallace et al., 2010). Due to the invisibility of ambient intelligence, Kosta, Pitkänen, et al. (2010) emphasise its partial uncontrollability. Amongst the attributes of ambient intelligence is its integration into everyday objects (Kosta, Pitkanen, et al., 2008; Kosta, Pitkänen, et al., 2010). As Cook et al. (2009) present it, the term 'ambient intelligence' refers to

"a digital environment that proactively, but sensibly, supports people in their daily lives." (Cook et al., 2009, p. 279) 
Hofmann (2012) calls the usage of ambient intelligence for actual help in everyday-tasks a welfare technology. According to the definition formulated by the Information Society and Technology Advisory Group (ISTAG) of the European Commission, ambient intelligence is a convergence of three major key technologies: ubiquitous computing, ubiquitous communication, and interfaces that adapt to the users (Darwish and Hassanien, 2011). According to Hofmann (2012), its aim is to provide better and more specific care and to reduce risks and therefore increase safety, making it possible for the vulnerable to increase their ability to cope and thus improve their capacity for self-determination, as well as enabling them to stay at home for longer before being institutionalised.

Ubiquitous computing in the context of (elderly) care is also referred to as health telematics (Friedewald and Raabe, 2011).

The term Ambient Assisted Living (AAL) refers to innovative technologies (relying on the field of ambient intelligence), intelligent systems of assistance that help elderly people (including those with disabilities, such as PwDs) in all stages of their life in order to extend their stay in their preferred environment, and to support systems that maintain the person's health and functional capabilities. This might promote a healthier lifestyle, thus allowing the elderly to continue an active and creative participation in their communities, and ultimately maintain or improve their quality of life. Moreover, AAL technologies may provide useful data that can be used to yield increased efficiency in care systems and care management. They may also provide remote mobile support for care-givers, thus alleviating the care-givers of certain tasks that can be automated (e.g. services for dressing, personal hygiene, drug intake reminder, etc.), or delivered at a more affordable cost (Broek et al., 2010).

The support and empowerment attributes of AAL technologies project the possible application of these technologies not only for PwDs exclusively but also to a wider cohort of (vulnerable) elderly in the future. Therefore, where the context of AAL technologies can be extended to the empowerment of the elderly in general, the terms PwD and elderly are used synonymously.

\subsection{Frequency of occurrence of most ethically relevant terms}

The usage frequency, namely, the number of different papers in which these terms occurred from our set of 186 papers, was measured.

The most frequent term used in the selected sources was 'home' (140 occurrences), which is understandable given that the purpose of AAL technologies is that of allowing PwD to stay at home for longer. A complete list of the usage frequencies of ethical terms is presented in Figure 4. 


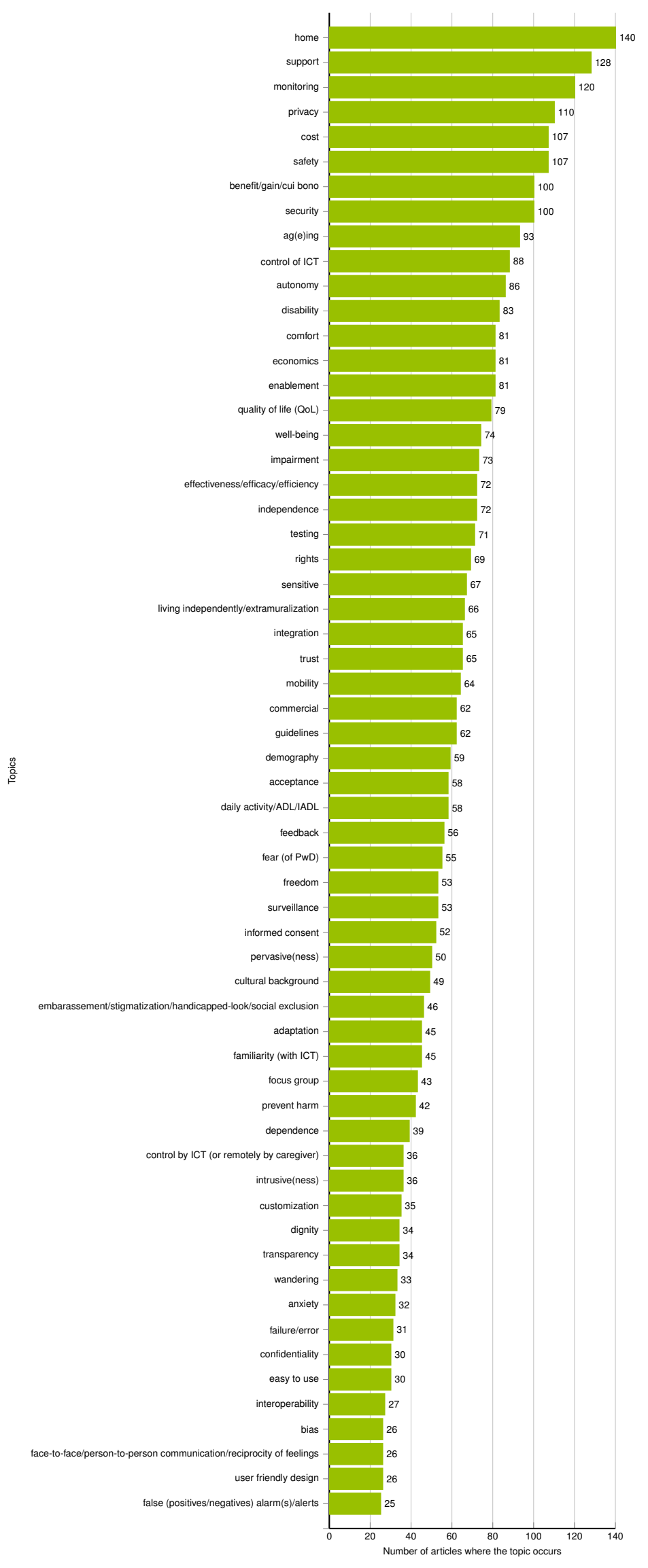

Figure 4: Frequency of ethical terms 


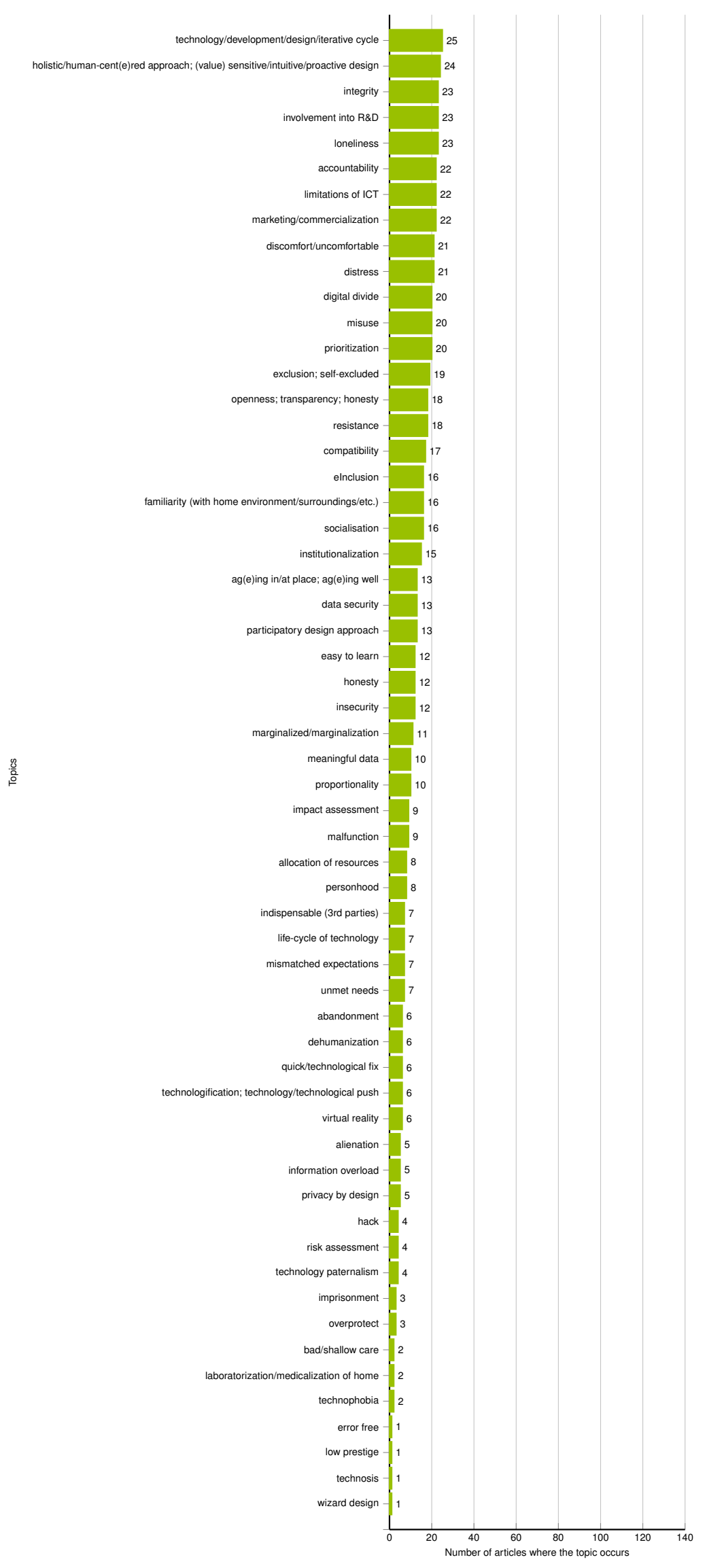

Figure 4: Frequency of ethical terms (cont.) 
Various ethical theories were applied in the publications for the analysis of AAL technologies: John Rawls' theory of justice (Doorn, 2010), Amartya Sen's capability approach (Coeckelbergh, 2010; Coeckelbergh, 2012; Toboso, 2011; Vallor, 2011), ethics of care of Carol Gilligan (Stapleton, 2008), Nel Noddings (Vallor, 2011), Joan Tronto (van Wynsberghe, 2012), and a criticism of evolutionary theories (Foddy, 2012).

\section{Results}

This results section presents an overview of the ethical issues raised by the usage of AAL technologies in the case of $\mathrm{PwD}$. These are presented here from the point of view of the stakeholders involved: the PwD, formal and informal care-givers (nurses, family proxies), researchers and clinicians, (software/hardware) engineers, designers, and technicians. These stakeholders involved in our ethical analysis had been previously defined by various authors (Allen et al., 2008; Duquenoy and Whitehouse, 2006; Duquenoy, 2004; Hofmann, 2012; R. Sparrow and L. Sparrow, 2006; Sponselee et al., 2008; van Hoof et al., 2011). For all these stakeholders we have listed the ethical issues present in the group of relevant articles that occur in three different stages of the technology: R\&D, clinical trials, and clinical application. The complete set of ethical issues mentioned in the literature is presented in Table 2 below, which is inspired by Mepham's methodology of ethical analysis ${ }^{5}$ with the help of an ethical matrix, adjusted to the needs of this literature review (Mepham, 2008). As Mepham's ethical matrix is fundamentally a checklist of concerns (Mepham, 2008, p. 63), we use it to provide in Table 2 a checklist of ethical issues, which are present during the various stages of $R \& D$, clinical trials and clinical application of AAL technologies. The matrix was then modified. Whenever an ethical issue was applicable to the sections both in the group of stakeholders or group of various stages of research, this was scored in the matrix.

\footnotetext{
${ }^{5}$ Mepham's methodology of ethical analysis is a practical framework that is designed to guide ethical analysis and discussion, which can lead to rational decision-making regarding competing requirements. However, the framework was not designed for prescriptive decision-making but rather as an ethical map. The framework involves the construction of a matrix, which first lists the interests of the various stakeholders (agents), then identifies the ethical requirements of these interests (based on three relevant prima facie principles: well-being, autonomy, fairness; representing the major traditional ethical theories: utilitarianism, deontological tradition, and modern social contract theory). Finally, the importance of each ethical requirement is rated (Mepham, 2008).
} 
Table 2 - Mepham's ethical matrix of ethical issues for AAL technologies used for PwD

\begin{tabular}{|c|c|c|c|}
\hline & Research \& Development (R\&D) & Clinical Trials & Clinical Application \\
\hline \multirow{31}{*}{ Persons with Dementia (PwD) } & Abandonment (lack of user involvement in R\&D) & AmI has "life on its own" & Acceptance \\
\hline & Dignity & Anxiety & Ageing at place \\
\hline & Familiarity & Control & Alienation \\
\hline & Feedback & Discomfort & Anxiety \\
\hline & Honesty & Easy-to-learn & Autonomy \\
\hline & Integrity & Easy-to-use & Comfort/discomfort \\
\hline & Involvement into R\&D & Enablement & Control \\
\hline & Mismatched expectations & Error-free & Cultural background \\
\hline & $\begin{array}{l}\text { Not only informed consent but interviews (simple } \\
\text { sentences TASC) }\end{array}$ & Failure, error & Customization \\
\hline & Participatory design approach & False (positives) alarm(s) & Daily activity (ADL, IADL) \\
\hline & Personhood & Fear & Dehumanization \\
\hline & Privacy by design & Home & Dependence \\
\hline & Risk assessment & Information overload & Digital divide \\
\hline & Safety & Informed consent & Dignity \\
\hline & Self-reports (Titration approach) & Insecurity & eInclusion \\
\hline & Special approach & Integration & $\begin{array}{l}\text { Embarrassment/stigmatization, handicapped-look, } \\
\text { social exclusion }\end{array}$ \\
\hline & \multirow[t]{15}{*}{ Virtual reality } & Intrusive(ness) & Enablement \\
\hline & & $\begin{array}{l}\text { Laboratorization of living } \\
\text { environment/medicalization of home }\end{array}$ & Error-free \\
\hline & & Mobility & Exclusion (self-excluded) \\
\hline & & Pervasive(ness) & $\begin{array}{l}\text { Face-to-face, person-to-person communication, } \\
\text { reciprocity of feelings }\end{array}$ \\
\hline & & Prevent harm (e.g. fall accidents) & Failure, error \\
\hline & & Privacy & False (positives) alarm(s) \\
\hline & & Resistance & Fear \\
\hline & & Safety & Freedom \\
\hline & & Security & Home \\
\hline & & Socializing & Impairment \\
\hline & & Special approach & Imprisonment \\
\hline & & Support & Independence \\
\hline & & Technophobia & Institutionalization \\
\hline & & Unmet needs & Integrity \\
\hline & & Voice control >LCD control & Limitation \\
\hline
\end{tabular}


Table 2 - continued from previous page

Clinical Trials

Clinical Application

Wandering

Living independently, extramuralization

Loneliness

Mobility

Monitoring

Pervasive(ness)

Prevent harm

Privacy

Quality of life (QoL)

Resistance

Safety

Security

Socializing

Support

Surveillance

Technophobia

Trust

Unmet needs

Wandering

Well-being

\section{Formal/Informal Care-givers \\ Continuous monitoring} (nurses, proxies)
Feedback

Focus groups

Honesty

Mismatched expectations

Monitoring

Privacy by design

Social exclusion/eInclusion

Who will gain?, whose benefit (cui bono)?
Acceptance

Easy-to-learn

Easy-to-use

Familiarity

Fear

Interoperability

Life-cycle of ICT

Limitations of ICT

Mismatched expectations

Misuse - whose responsibility?

Overprotection

Prevent harm

Reciprocal accountability

Resistance

\section{Acceptance}

Against institutionalization (ageing at place)

Bad care/shallow care

Cultural background

Dehumanization

Dependence

Dignity

Easy-to-learn

Easy-to-use

Effectiveness

Efficacy

Efficiency

Enablement

Face-to-face, person-to-person communication, reciprocity of feelings 
Table 2 - continued from previous page

\begin{tabular}{|c|c|c|c|}
\hline & Research \& Development (R\&D) & Clinical Trials & Clinical Application \\
\hline & & $\begin{array}{l}\text { Safety } \\
\text { Security } \\
\text { Technophobia } \\
\text { Trust } \\
\text { Unmet needs } \\
\text { User-friendly design } \\
\text { Well-being }\end{array}$ & $\begin{array}{l}\text { Familiarity } \\
\text { Impairment } \\
\text { Institutionalization } \\
\text { Interoperability } \\
\text { Life-cycle of ICT } \\
\text { Mismatched expectations } \\
\text { Misuse - whose responsibility? } \\
\text { Monitoring } \\
\text { Overprotection } \\
\text { Quality of life (QoL) } \\
\text { Reciprocal accountability } \\
\text { Resistance } \\
\text { Support } \\
\text { Technologification, technology push, technological } \\
\text { push } \\
\text { Technology paternalism } \\
\text { Technophobia } \\
\text { Trust } \\
\text { Unmet needs } \\
\text { User-friendly design } \\
\text { Well-being }\end{array}$ \\
\hline \multirow[t]{2}{*}{ Researchers and Clinicians } & $\begin{array}{l}\text { Allocation of resources } \\
\text { Continuous monitoring } \\
\text { Dignity } \\
\text { Holistic approach, human-centred approach, } \\
\text { human-centered approach, (value) sensitive design, } \\
\text { intuitive design, proactive design }\end{array}$ & $\begin{array}{l}\text { Bias } \\
\text { Confidentiality } \\
\text { Daily activity (ADL/IADL) } \\
\text { Data security }\end{array}$ & $\begin{array}{l}\text { Bad care/shallow care } \\
\text { Bias } \\
\text { Confidentiality } \\
\text { Data security }\end{array}$ \\
\hline & $\begin{array}{l}\text { Personhood } \\
\text { Who will gain?, whose benefit (cui bono)? }\end{array}$ & $\begin{array}{l}\text { Dignity } \\
\text { Disability } \\
\text { Easy-to-learn } \\
\text { Easy-to-use } \\
\text { Honesty } \\
\text { Informed consent } \\
\text { Laboratorization of living } \\
\text { environment/medicalization of home }\end{array}$ & $\begin{array}{l}\text { Dignity } \\
\text { Disability } \\
\text { Easy-to-learn } \\
\text { Easy-to-use } \\
\text { Effectiveness } \\
\text { Enablement } \\
\text { Honesty }\end{array}$ \\
\hline
\end{tabular}




\section{Life-cycle of ICT}

Meaningful data collection

Misuse - whose responsibility?

Monitoring

Overprotection

Personhood

Prevent harm (e.g. fall accidents)

Prioritization of medical data

Proportionality

Reduce insecurity

Reliability

Rights

Safety

Security

Trust

Well-being
Human-centred approach

Impairment

Independence

Integration

Interoperability

Is the person really in a need for AmI?

Life-cycle of ICT

Living independently, extramuralization

Misuse - whose responsibility?

Mobility

Monitoring

Overprotection

Prevent harm

Prioritization of medical data

Proportionality

Quality of life (QoL)

Reliability

Rights

Safety

Security

Socializing

Support

Trust

Well-being

What is normal ADL/IADL?

Customization

Failure, error

Compatibility

False (positives) alarm(s)

Bandwidth prioritization

Comfort/discomfort

Commercial

Cost

Data security

Home

Data security

DoS attacks

Indispensability of 3rd parties

Easy-to-learn

Error-free

Failure, error

False (positives) alarm(s)
Hacks

Impact assessment
Interoperability

Laboratorization of living

environment/medicalization of hom 


\begin{tabular}{|c|c|c|c|}
\hline & Integration & Life-cycle of ICT & Home \\
\hline & Interoperability & Limitations of ICT & Imprisonment \\
\hline & Low prestige ICT development & Meaningful data & Information overload \\
\hline & Mismatched expectations & What is normal ADL/IADL? & Interoperability \\
\hline & Mobility & Prioritization & Life-cycle of ICT \\
\hline & Participatory design approach & Privacy by design & Limitations of ICT \\
\hline & Quick fix, technological fix & Resistance & Prioritization \\
\hline & Resistance & Risk assessment & Proportionality \\
\hline & Risk assessment & Safety & Quick fix, technological fix \\
\hline & Special approach & Security & Safety \\
\hline & $\begin{array}{l}\text { Technologification, technology push, technological } \\
\text { push }\end{array}$ & $\begin{array}{l}\text { Technologification, technology push, technological } \\
\text { push }\end{array}$ & Security \\
\hline & Technology paternalism & Technology paternalism & Support \\
\hline & & Trust & Trust \\
\hline & & Unmet needs & \\
\hline & & Very few testing in actual homes & \\
\hline \multirow[t]{10}{*}{ Designers } & Acceptance & Acceptance & Acceptance \\
\hline & Alienation & Adaptation & Adaptation \\
\hline & Anxiety & Anxiety & Anxiety \\
\hline & Bias & Comfort & Comfort/discomfort \\
\hline & Dehumanization & Control & Commercial \\
\hline & Design-for-all approach & Customization & Compatibility \\
\hline & Dignity & Dignity & Control \\
\hline & Feedback & Discomfort (e.g. battery, etc.) & Cost \\
\hline & Focus groups & Familiarity & Cultural background \\
\hline & Impact assessment & Indispensability (of $3^{\text {rd }}$ parties) & Customization \\
\hline
\end{tabular}




\begin{tabular}{|c|c|c|c|}
\hline & Research \& Development (R\&D) & Clinical Trials & Clinical Application \\
\hline & Intrusive(ness) & Integration & Dependence \\
\hline & $\begin{array}{l}\text { Involvement into R\&D (participatory design } \\
\text { approach) }\end{array}$ & Intrusive(ness) & Digital divide \\
\hline & Mismatched expectations & Laboritarization/medicalization of home & Dignity \\
\hline & Privacy by design & Life-cycle of ICT & Easy-to-learn \\
\hline & Proactive design & Limitations of ICT & Easy-to-use \\
\hline & Risk assessment & Mismatched expectations & Efficiency \\
\hline & Safety & Misuse - whose responsibility? & $\begin{array}{l}\text { Embarrassment/stigmatization, handicapped-look, } \\
\text { social exclusion }\end{array}$ \\
\hline & Sensitive & Prevent harm (e.g. fall accidents) & Enablement \\
\hline & Special approach & Resistance & Ergonomics \\
\hline & Testing & Support & Failure, error \\
\hline & Trust & $\begin{array}{l}\text { Technologification, technology push, technological } \\
\text { push }\end{array}$ & Familiarity \\
\hline & Unmet needs & Technology paternalism & Indispensability (of $3^{\text {rd }}$ parties) \\
\hline & User friendly design & Technophobia & Integration \\
\hline & Wizard design & Testing & Integrity \\
\hline & & Trust & Interoperability \\
\hline & & Unmet needs & Laboritarisation/medicalisation of home \\
\hline & & & Life-cycle of ICT \\
\hline & & & Limitations of ICT \\
\hline & & & Marketing \\
\hline & & & Misuse - whose responsibility? \\
\hline & & & Mobility \\
\hline & & & Prevent harm \\
\hline & & & Resistance \\
\hline & & & $\begin{array}{l}\text { Technologification, technology push, technological } \\
\text { push }\end{array}$ \\
\hline & & & Technology paternalism \\
\hline & & & Technophobia \\
\hline Technicians & & Home & Indispensability (of $3^{\text {rd }}$ parties) \\
\hline & & Sensitive installation of devices & Special approach during maintenance \\
\hline & & Trust & Support \\
\hline & & & Trust \\
\hline
\end{tabular}


As stated earlier, we structured our analysis of the field in terms of the stakeholders (PwDs, formal and informal care-givers, researchers and clinicians, engineers, designers, and technicians) and for each of these we categorized the literature in terms of issues to do with R\&D, clinical trials, clinical application. Table 3 shows the distribution of the literature across this categorization and in the remainder of this section we examine each of the issues for each of the stakeholder groups, in turn. 
Table 3 - Overview of the ethical issues in the resulted literature

\begin{tabular}{|c|c|c|c|c|c|c|}
\hline & Person with dementia & $\begin{array}{l}\text { Formal caregivers, informal } \\
\text { proxies }\end{array}$ & Researchers, clinicians & $\begin{array}{l}\text { Software/hardware } \\
\text { engineers }\end{array}$ & Designers & Technicians \\
\hline $\begin{array}{l}\text { User involvement in } \\
\text { R\&D }\end{array}$ & $\begin{array}{l}\text { Francis et al. (2009), Wallace } \\
\text { et al. (2010) }\end{array}$ & & & $\begin{array}{l}\text { Francis et al. (2009), } \\
\text { Gaul and Ziefle (2009) }\end{array}$ & $\begin{array}{l}\text { Allen et al. (2008), Aarts } \\
\text { et al. (2007), } \\
\text { Borenstein and } \\
\text { Pearson (2010), } \\
\text { Burleson et al. (2012), } \\
\text { Duquenoy (2004), } \\
\text { Francis et al. (2009), } \\
\text { Hersh et al. (2003), } \\
\text { Kosta, Pitkanen, et al. } \\
\text { (2008), Kosta, } \\
\text { Pitkänen, et al. (2010), } \\
\text { Lorenzen-Huber et al. } \\
\text { (2011), Maguire et al. } \\
\text { (2011), Maier and } \\
\text { Kempter (2009), } \\
\text { Newell et al. (2011), } \\
\text { O'Neill, Parente, et al. } \\
\text { (2011), Picking et al. } \\
\text { (2012), Pulli et al. } \\
\text { (2012), Sponselee et al. } \\
\text { (2008), Wallace et al. } \\
\text { (2010), Wright (2011) }\end{array}$ & \\
\hline
\end{tabular}


Table 3 - continued from previous page

\begin{tabular}{|c|c|c|c|c|c|c|}
\hline & Person with dementia & $\begin{array}{l}\text { Formal caregivers, informal } \\
\text { proxies }\end{array}$ & Researchers, clinicians & $\begin{array}{l}\text { Software/hardware } \\
\text { engineers }\end{array}$ & Designers & Technicians \\
\hline Acceptance of ICT & $\begin{array}{l}\text { Abascal and Azevedo } \\
\text { (2007), Duquenoy and } \\
\text { Whitehouse (2006), } \\
\text { Fairclough (2009), Francis } \\
\text { et al. (2009), Gaul and } \\
\text { Ziefle (2009), Grönvall } \\
\text { and Kyng (2012), } \\
\text { Holzinger et al. (2008), } \\
\text { S. Lauriks et al. (2007), } \\
\text { Steve Lauriks et al. (2010), } \\
\text { Mordini et al. (2009), } \\
\text { O'Neill, Mason, et al. } \\
\text { (2011), Oppenauer et al. } \\
\text { (2007), Panek and Zagler } \\
\text { (2008), Portet et al. (2011), } \\
\text { Remmers (2010), Salces } \\
\text { et al. (2006), Sponselee } \\
\text { et al. (2008), van Hoof } \\
\text { et al. (2011), Wallace et al. } \\
\text { (2010), Zaad and } \\
\text { Ben Allouch (2008) }\end{array}$ & & & & & \\
\hline $\begin{array}{l}\text { Informed consent, } \\
\text { independence, } \\
\text { self-determination }\end{array}$ & $\begin{array}{l}\text { Hofmann (2012), Kosta, } \\
\text { Pitkänen, et al. (2010), } \\
\text { Picking et al. (2012), } \\
\text { Remmers (2010), Scanaill } \\
\text { et al. (2006) }\end{array}$ & & & & & \\
\hline Control, customisation & $\begin{array}{l}\text { Decker (2012), Duquenoy } \\
\text { and Whitehouse (2006), } \\
\text { Kang et al. (2010), Kosta, } \\
\text { Pitkänen, et al. (2010), } \\
\text { Portet et al. (2011), } \\
\text { van Hoof et al. (2011), } \\
\text { Wallace et al. (2010), Zaad } \\
\text { and Ben Allouch (2008) }\end{array}$ & & & & & \\
\hline
\end{tabular}


Table 3 - continued from previous page

\begin{tabular}{|c|c|c|c|c|c|c|}
\hline & Person with dementia & $\begin{array}{l}\text { Formal caregivers, informal } \\
\text { proxies }\end{array}$ & Researchers, clinicians & $\begin{array}{l}\text { Software/hardware } \\
\text { engineers }\end{array}$ & Designers & Technicians \\
\hline $\begin{array}{l}\text { Prevention of harm, } \\
\text { medicalization of } \\
\text { home environment }\end{array}$ & $\begin{array}{l}\text { Ahonen et al. (2010), } \\
\text { Batchelor et al. (2012), } \\
\text { Belbachir et al. (2010), } \\
\text { Cavoukian et al. (2010), } \\
\text { Chan, Estève, et al. (2008), } \\
\text { Friedewald and Raabe } \\
\text { (2011), Hofmann (2012), } \\
\text { Kosta, Pitkänen, et al. } \\
\text { (2010), Landau and } \\
\text { Werner (2012), Piasek et al. } \\
\text { (2013), Sponselee et al. } \\
\text { (2008), van Hoof et al. } \\
\text { (2011) }\end{array}$ & & & & & \\
\hline $\begin{array}{l}\text { Ageing at home, } \\
\text { autonomy, } \\
\text { dependence on a } \\
\text { system }\end{array}$ & $\begin{array}{l}\text { Darwish and Hassanien } \\
\text { (2011), Harrefors et al. } \\
\text { (2012), Kosta, Pitkanen, } \\
\text { et al. (2008), Kosta, } \\
\text { Pitkänen, et al. (2010), } \\
\text { Maguire et al. (2011), } \\
\text { Portet et al. (2011), } \\
\text { van Hoof et al. (2011) }\end{array}$ & & & & & \\
\hline
\end{tabular}


Table 3 - continued from previous page

\begin{tabular}{|c|c|c|c|c|c|c|}
\hline & Person with dementia & $\begin{array}{l}\text { Formal caregivers, informal } \\
\text { proxies }\end{array}$ & Researchers, clinicians & $\begin{array}{l}\text { Software/hardware } \\
\text { engineers }\end{array}$ & Designers & Technicians \\
\hline $\begin{array}{l}\text { Embarrassment, } \\
\text { stigmatization, social } \\
\text { isolation }\end{array}$ & $\begin{array}{l}\text { Kumar and Lee (2011), } \\
\text { Chan, Campo, et al. (2009), } \\
\text { Dishman and Carrillo } \\
\text { (2007), Fairclough (2009), } \\
\text { Francis et al. (2009), Kosta, } \\
\text { Pitkänen, et al. (2010), } \\
\text { Martin et al. (2010), } \\
\text { McLean (2011), O'Neill, } \\
\text { Mason, et al. (2011), } \\
\text { Oppenauer et al. (2007), } \\
\text { Palm (2012), Portet et al. } \\
\text { (2011), Louise Robinson } \\
\text { et al. (2009), Salces et al. } \\
\text { (2006), A. Sixsmith and } \\
\text { J. Sixsmith (2008), Sorell } \\
\text { and Draper (2012), } \\
\text { Sponselee et al. (2008), } \\
\text { Kleinberger et al. (2007), } \\
\text { van Hoof et al. (2011), } \\
\text { Wright (2011), Wright and } \\
\text { Wadhwa (2010), Zwijsen } \\
\text { et al. (2010) }\end{array}$ & & & & & \\
\hline $\begin{array}{l}\text { Monitoring, } \\
\text { surveillance }\end{array}$ & $\begin{array}{l}\text { Gaul and Ziefle (2009), } \\
\text { Grönvall and Kyng (2012), } \\
\text { Hofmann (2012), Kaye } \\
\text { (2010), Kosta, Pitkanen, } \\
\text { et al. (2008), Kosta, } \\
\text { Pitkänen, et al. (2010), } \\
\text { Lynch et al. (2009), } \\
\text { Mordini et al. (2009), } \\
\text { Oppenauer et al. (2007), } \\
\text { Remmers (2010), Salces } \\
\text { et al. (2006) }\end{array}$ & & & & & \\
\hline
\end{tabular}


Table 3 - continued from previous page

\begin{tabular}{|c|c|c|c|c|c|c|}
\hline & Person with dementia & $\begin{array}{l}\text { Formal caregivers, informal } \\
\text { proxies }\end{array}$ & Researchers, clinicians & $\begin{array}{l}\text { Software/hardware } \\
\text { engineers }\end{array}$ & Designers & Technicians \\
\hline $\begin{array}{l}\text { Social exclusion, digital } \\
\text { divide, familiarity } \\
\text { with ICT, affordability }\end{array}$ & $\begin{array}{l}\text { Abascal and Nicolle (2005), } \\
\text { Batchelor et al. (2012), } \\
\text { Daniel et al. (2009), } \\
\text { Francis et al. (2009), } \\
\text { Hofmann (2012), Kosta, } \\
\text { Pitkanen, et al. (2008), } \\
\text { Kosta, Pitkänen, et al. } \\
\text { (2010), McLean (2011), } \\
\text { Mordini et al. (2009), } \\
\text { Niemelä et al. (2007), } \\
\text { Oppenauer et al. (2007), } \\
\text { Satava (2003), Walsh and } \\
\text { Callan (2011), Wright and } \\
\text { Wadhwa (2010), Zaad and } \\
\text { Ben Allouch (2008), } \\
\text { Zwijsen et al. (2010) }\end{array}$ & & & & & \\
\hline Benefit & & $\begin{array}{l}\text { Darwish and Hassanien } \\
\text { (2011), Hofmann (2012) }\end{array}$ & & & & \\
\hline $\begin{array}{l}\text { Data collection, safety, } \\
\text { protection }\end{array}$ & & Fairclough (2009) & & $\begin{array}{l}\text { Abascal and Azevedo } \\
\text { (2007), Chan, Estève, } \\
\text { et al. (2008), } \\
\text { Duquenoy (2004), } \\
\text { Kosta, Pitkanen, et al. } \\
\text { (2008), Kumar and } \\
\text { Lee (2011) }\end{array}$ & & \\
\hline $\begin{array}{l}\text { Prevalence of } \\
\text { technological } \\
\text { rationality in human } \\
\text { care }\end{array}$ & & $\begin{array}{l}\text { Dekkers (2009), Hofmann } \\
\text { (2012), Oost and Reed } \\
\text { (2011), R. Sparrow and } \\
\text { L. Sparrow (2006), } \\
\text { Sponselee et al. (2008) }\end{array}$ & & & & \\
\hline
\end{tabular}


Table 3 - continued from previous page

\begin{tabular}{|c|c|c|c|c|c|c|}
\hline & Person with dementia & $\begin{array}{l}\text { Formal caregivers, informal } \\
\text { proxies }\end{array}$ & Researchers, clinicians & $\begin{array}{l}\text { Software/hardware } \\
\text { engineers }\end{array}$ & Designers & Technicians \\
\hline $\begin{array}{l}\text { Instrumentalisation of } \\
\text { care, the value of } \\
\text { human care, tasks not } \\
\text { suitable for ICT }\end{array}$ & & $\begin{array}{l}\text { Borenstein and Pearson } \\
\text { (2010), Coeckelbergh } \\
\text { (2010), Hofmann (2012), } \\
\text { Oost and Reed (2011), } \\
\text { Portet et al. (2011), } \\
\text { A. Sharkey and } \\
\text { N. Sharkey (2012), } \\
\text { R. Sparrow and } \\
\text { L. Sparrow (2006), Stip } \\
\text { and Rialle (2005), Vallor } \\
\text { (2011), Walsh and Callan } \\
\text { (2011) }\end{array}$ & & $\begin{array}{l}\text { Hofmann (2012), } \\
\text { R. Sparrow and } \\
\text { L. Sparrow (2006) }\end{array}$ & & \\
\hline $\begin{array}{l}\text { Overprotection, } \\
\text { paternalism, previous } \\
\text { working habits, rigid } \\
\text { application of } \\
\text { protocols }\end{array}$ & & $\begin{array}{l}\text { Martin et al. (2010), } \\
\text { Sponselee et al. (2008), } \\
\text { L. Robinson et al. (2007) }\end{array}$ & & & & \\
\hline $\begin{array}{l}\text { Not-invented-here } \\
\text { syndrome }\end{array}$ & & Sponselee et al. (2008) & & & & \\
\hline $\begin{array}{l}\text { Motives for } \\
\text { participation in } \\
\text { research, eagerness to } \\
\text { please, power } \\
\text { relationship }\end{array}$ & & & $\begin{array}{l}\text { Grönvall and Kyng (2012), } \\
\text { Maier and Kempter (2009), } \\
\text { Oberzaucher et al. (2009), } \\
\text { Wallace et al. (2010) }\end{array}$ & & $\begin{array}{l}\text { Brown et al. (2004), } \\
\text { Brown et al. (2006), } \\
\text { Francis et al. (2009), } \\
\text { Maier and Kempter } \\
\text { (2009), Sponselee et al. } \\
\text { (2008), Wallace et al. } \\
\text { (2010), Walsh and } \\
\text { Callan (2011) }\end{array}$ & \\
\hline
\end{tabular}


Table 3 - continued from previous page

\begin{tabular}{|c|c|c|c|c|c|c|}
\hline & Person with dementia & $\begin{array}{l}\text { Formal caregivers, informal } \\
\text { proxies }\end{array}$ & Researchers, clinicians & $\begin{array}{l}\text { Software/hardware } \\
\text { engineers }\end{array}$ & Designers & Technicians \\
\hline $\begin{array}{l}\text { Meaningfulness and } \\
\text { prioritization of data }\end{array}$ & & & $\begin{array}{l}\text { Allen et al. (2008), Conley } \\
\text { et al. (2008), Cook et al. } \\
\text { (2009), Darwish and } \\
\text { Hassanien (2011), Kang } \\
\text { et al. (2010), Kaye (2010), } \\
\text { Noury et al. (2011), } \\
\text { Romdhane et al. (2012), } \\
\text { Sponselee et al. (2008), } \\
\text { Viswanathan et al. (2012), } \\
\text { Wherton and Monk (2008) }\end{array}$ & & & \\
\hline Safety and security & & & $\begin{array}{l}\text { Hofmann (2012), S. Lauriks } \\
\text { et al. (2007) }\end{array}$ & $\begin{array}{l}\text { Chan, Estève, et al. } \\
\text { (2008), Darwish and } \\
\text { Hassanien (2011) }\end{array}$ & & \\
\hline $\begin{array}{l}\text { Human-centred } \\
\text { approach }\end{array}$ & & & $\begin{array}{l}\text { Hofmann (2012), Portet } \\
\text { et al. (2011), Scanaill et al. } \\
\text { (2006), Zaad and } \\
\text { Ben Allouch (2008) }\end{array}$ & & & \\
\hline Allocation of resources & & & Duquenoy (2004) & & & \\
\hline $\begin{array}{l}\text { ICT and diagnosis, } \\
\text { automated machine } \\
\text { diagnosis }\end{array}$ & & & $\begin{array}{l}\text { Camarinha-Matos and } \\
\text { Afsarmanesh (2011), Chan, } \\
\text { Estève, et al. (2008), } \\
\text { Darwish and Hassanien } \\
\text { (2011), Dishman and } \\
\text { Carrillo (2007), } \\
\text { Friedewald and Raabe } \\
\text { (2011), Fairclough (2009), } \\
\text { Gaul and Ziefle (2009), } \\
\text { Hofmann (2012), Kosta, } \\
\text { Pitkanen, et al. (2008), } \\
\text { Kosta, Pitkänen, et al. } \\
\text { (2010), Merilahti et al. } \\
\text { (2012), Plaza et al. (2011), } \\
\text { Palm (2012), Kleinberger } \\
\text { et al. (2007) }\end{array}$ & & & \\
\hline
\end{tabular}


Table 3 - continued from previous page

\begin{tabular}{|c|c|c|c|c|c|c|}
\hline & Person with dementia & $\begin{array}{l}\text { Formal caregivers, informal } \\
\text { proxies }\end{array}$ & Researchers, clinicians & $\begin{array}{l}\text { Software/hardware } \\
\text { engineers }\end{array}$ & Designers & Technicians \\
\hline $\begin{array}{l}\text { Technical or 'quick' fix, } \\
\text { R\&D for PwD as low } \\
\text { prestige endeavour }\end{array}$ & & & & $\begin{array}{l}\text { Hofmann (2012), } \\
\text { Mordini et al. (2009) }\end{array}$ & & \\
\hline $\begin{array}{l}\text { Mismatched } \\
\text { expectations }\end{array}$ & & & & $\begin{array}{l}\text { Allen et al. } \\
\text { (2008),Duquenoy and } \\
\text { Whitehouse (2006), } \\
\text { Duquenoy (2004), } \\
\text { van Hoof et al. (2011) }\end{array}$ & & \\
\hline $\begin{array}{l}\text { Interoperability, } \\
\text { compatibility of } \\
\text { systems }\end{array}$ & & & & $\begin{array}{l}\text { Chan, Estève, et al. } \\
\text { (2008), Darwish and } \\
\text { Hassanien (2011), } \\
\text { Román et al. (2009) }\end{array}$ & & \\
\hline $\begin{array}{l}\text { Special status of human } \\
\text { experimentation }\end{array}$ & & & & Mordini et al. (2009) & & \\
\hline $\begin{array}{l}\text { Indispensable third } \\
\text { parties }\end{array}$ & & & & $\begin{array}{l}\text { Decker (2012), } \\
\text { Hofmann (2012), } \\
\text { Kosta, Pitkänen, et al. } \\
\text { (2010), van Hoof et al. } \\
\text { (2011), Wright (2011) }\end{array}$ & & van Hoof et al. (2011) \\
\hline $\begin{array}{l}\text { Testing of AAL } \\
\text { technologies, impact } \\
\text { assessment }\end{array}$ & & & & $\begin{array}{l}\text { Hofmann (2012), Portet } \\
\text { et al. (2011) }\end{array}$ & $\begin{array}{l}\text { Cahill et al. (2007), } \\
\text { Chan, Estève, et al. } \\
\text { (2008), Chan, Campo, } \\
\text { et al. (2009), } \\
\text { Steve Lauriks et al. } \\
\text { (2010), Portet et al. } \\
\text { (2011), Scanaill et al. } \\
\text { (2006), Wright (2011) }\end{array}$ & \\
\hline $\begin{array}{l}\text { Principle of } \\
\text { proportionality }\end{array}$ & & & & Hofmann (2012) & & \\
\hline $\begin{array}{l}\text { Easy to learn, error free } \\
\text { ICT }\end{array}$ & & & & Portet et al. (2011) & & \\
\hline
\end{tabular}


Table 3 - continued from previous page

\begin{tabular}{|c|c|c|c|c|c|c|}
\hline & Person with dementia & $\begin{array}{l}\text { Formal caregivers, informal } \\
\text { proxies }\end{array}$ & Researchers, clinicians & $\begin{array}{l}\text { Software/hardware } \\
\text { engineers }\end{array}$ & Designers & Technicians \\
\hline $\begin{array}{l}\text { Different life-cycle of } \\
\text { technology and } \\
\text { service, technology } \\
\text { push }\end{array}$ & & & & $\begin{array}{l}\text { Chan, Campo, et al. } \\
\text { (2009), Kosta, } \\
\text { Pitkanen, et al. (2008), } \\
\text { Kosta, Pitkänen, et al. } \\
\text { (2010) }\end{array}$ & & \\
\hline $\begin{array}{l}\text { The role of AAL } \\
\text { technologies }\end{array}$ & & & & Rapoport (2012) & & \\
\hline $\begin{array}{l}\text { Design-for-all approach, } \\
\text { heteronomous group } \\
\text { of PwD }\end{array}$ & & & & & $\begin{array}{l}\text { Abascal and Azevedo } \\
\text { (2007), Darwish and } \\
\text { Hassanien (2011), } \\
\text { Duquenoy and } \\
\text { Whitehouse (2006), } \\
\text { Kosta, Pitkanen, et al. } \\
\text { (2008), Kosta, } \\
\text { Pitkänen, et al. (2010), } \\
\text { Newell et al. (2011), } \\
\text { Portet et al. (2011), } \\
\text { Sponselee et al. (2008), } \\
\text { Wallace et al. (2010) }\end{array}$ & \\
\hline Definition of disability & & & & & $\begin{array}{l}\text { Abascal and Nicolle } \\
\text { (2005), Appleyard } \\
\text { (2005), Darzentas and } \\
\text { Miesenberger (2005), } \\
\text { Lynch et al. (2009) }\end{array}$ & \\
\hline $\begin{array}{l}\text { Sensitive installation of } \\
\text { devices }\end{array}$ & & & & & & van Hoof et al. (2011) \\
\hline
\end{tabular}




\subsection{Persons with Dementia}

\subsubsection{R\&D}

User involvement in $R \mathcal{E} D$ : Persons with mild cognitive impairment (MCI) have special needs and requirements, which may not be immediately apparent to developers and researchers (Wallace et al., 2010). Wallace et al. (2010) emphasise the importance of providing feedback from the user to reduce possible errors in the product while Francis et al. (2009) suggest that a new technology might be rejected and abandoned by its potential users, if they have not been directly involved in the R\&D process from the very beginning.

Acceptance of ICT: Panek and Zagler (2008) report that the user needs are usually illunderstood during the processes of $R \& D$ and implementation, and according to $S$. Lauriks et al. (2007) and Steve Lauriks et al. (2010), there are several unmet needs (general and personalised information; support with regarding symptoms of dementia; socialisation; health monitoring and perceived safety). Users' cultural differences and backgrounds play a significant role in the acceptance of ICT (Duquenoy and Whitehouse, 2006). A very important aspect for the acceptance of ICT amongst the elderly, according to many authors, is the motivation of the user (Gaul and Ziefle, 2009; Grönvall and Kyng, 2012; Holzinger et al., 2008; Remmers, 2010; Salces et al., 2006; van Hoof et al., 2011). With correct motivation, a greater intention to use the ICT devices can be reached by the elderly (Zaad and Ben Allouch, 2008) who are willing to accept technology if it is worth the effort (Wallace et al., 2010). It has been reported that designers are usually less successful than relatives in motivating users to use ICT devices (Sponselee et al., 2008). Relatives can have a major impact on PwD's subjective norms for ICT acceptance (Steve Lauriks et al., 2010; Zaad and Ben Allouch, 2008). Training and education also play an important role in ICT acceptance (Mordini et al., 2009; Oppenauer et al., 2007).

Authors disagree on the functionalities of ICT devices, with some proposing that they should be reduced (Wallace et al., 2010) and others proposing that they should be extended by providing more alarms and more functions (Zaad and Ben Allouch, 2008). It should be borne in mind that the elderly (even those with mild dementia) are still able to learn, albeit in a different way than usual (Wallace et al., 2010). Nevertheless, overly complex systems with multiple-step procedures that place high learning requirements on the diminished capabilities of PwDs have a greater likelihood of failure ( $\mathrm{O}^{\prime}$ Neill, Mason, et al., 2011; Wallace et al., 2010). For instance, blinking LEDs or vibrating sounds (van Hoof et al., 2011), a screw head looking like a button (O'Neill, Mason, et al., 2011), or an amount of newly installed cables (van Hoof et al., 2011) can cause confusion or frustration and can also have a major impact on the overall acceptance of the technology for the user. PwDs will also have to learn to cope with AAL technologies, when employing these assistive tools (Portet et al., 2011). A further way of enhancing the acceptability of a system for the user is by the provision of sufficient customisation, adaptation possibilities or high quality products (Abascal and Azevedo, 2007; Francis et al., 2009).

Fairclough (2009) recommends the use of a 'titration' approach while defining the needs of a vulnerable ICT user, which employs subjective self-reports to standardise and personalise the various experiences of each participant, to provide a more objective and 
scientific evaluation. Moreover, Francis et al. (2009) propose using the recommendations of the The Autism Simplex Collection (TASC) project (1998), which involves using visual communication tools for less-verbal users during the interview questions, thus helping to introduce these participants actively into the process of $R \& D$, without recourse to using abstract and complicated concepts.

\subsubsection{Clinical Trials}

Informed consent, independence and self-determination: During the clinical trial period, the vulnerability of the PwD could raise certain questions regarding informed consent as to the hi-tech nature of AAL technology may make it difficult for a PwD to fully understand what their consent is being sought for. PwDs could become dependent on AAL technology to such an extent that it reduces their autonomy (e.g. a user who is over-dependent on a system may wait for the system to report a complication on her behalf, instead of reporting it directly herself (Scanaill et al., 2006)). This dependence on the (hi-tech) pseudo-intelligence provided by AAL technologies means that, while they empower very specific faculties, they can reduce people's autonomy. Consequently, they could also dramatically infringe the validity of informed consent given by PwD at the more advanced stages of their AAL usage (Hofmann, 2012). Also, the ambient functioning of the AAL technology in the private homes of PwDs would mean that additional informed consent would be needed from co-habitants (Hofmann, 2012). Moreover, Kosta, Pitkänen, et al. (2010) criticise the opt-out policy, which weakens personal autonomy and thereby the decision-making of the user.

Remmers (2010) points out that the reduction of independence does not automatically result in an incapacity of self-determination. ${ }^{6}$ According to him, the longest possible preservation of self-determination is the main normative background legitimising the usage of assistive technologies in the home. Reciprocal dependency on other humans is unavoidable because it is impossible for any human being to lead a completely independent, self-determined life without at least once in their lifetime (e.g. childhood, teenage years, etc.) needing support and aid. The use of assistive technologies is mostly justified when the need for such support emerges and the compensating functions of technologies are intended, resulting in a regained personal self-determination. Thus, the form and consequences of dependency linked with the use of assistive technologies extend only to the dependency on a technical instrument (Remmers, 2010).

Picking et al. (2012) mention that researchers welcome the development of a certain amount of dependency on a product, if the product provides support for independent living. After all, according to Remmers (2010), such self-induced dependencies on artefacts are typical of modern civilisation.

Control of ICT, customisation: Wallace et al. (2010) emphasise the different perception of technology by PwDs, who might consider technology as not meant for them: the system is not of any use to them, or not even relevant to them at all.

\footnotetext{
${ }^{6}$ Remmers defines self-determination, based on the traditions of the Stoics, Cicero, later Thomism, the natural law tradition of Pufendorf, and Kantian philosophy as: 'freedom from constraint'. Selfdetermination tightly linked with human dignity is normatively a basic right, however it is acquired on a genealogical level (biographical development of personal abilities). (Remmers, 2010)
} 
One of the major worries expressed by Kosta, Pitkänen, et al. (2010) is that the PwDs, when dealing with ambient technologies, will lack necessary control, becoming prisoners of AAL technologies in their own homes. van Hoof et al. (2011) reported that a high number of false alarms resulted in annoyance in some users, partially because the falsity of the alarm needed to be verified through confirmation by the user, otherwise it was automatically considered to be a true alarm.

During clinical trials, certain users reported fears about these technologies having a 'life of their own'. There is a risk that users might find the technologies obtrusive (Portet et al., 2011). During trials, it has been observed that some persons with physical or mild cognitive impairment prefer using voice commands to touchscreen control of the devices (Portet et al., 2011), while others found the touchscreen control equally beneficial (Wallace et al., 2010). In a discussion of the use of robots, Decker (2012) emphasises that although it is recommended that a veto function should exist to allow users to stop the robots' actions, this view has been challenged where persons with cognitive impairment are concerned. Also, some authors point out that during a trial, the participants had to be protected against information overload (Duquenoy and Whitehouse, 2006; Kang et al., 2010).

Zaad and Ben Allouch (2008) also mention the possible 'compassionate interference' between the user and care-giver. While users expressed their wishes for more direct control over ICT devices, the care-givers however wanted to prevent a user having control over the supporting system (in some cases). Often, at first glance, it is not clear who the real user of the system is. Therefore, user controllability and user-centeredness does not overlap in all cases (Zaad and Ben Allouch, 2008).

Prevention of harm, pervasiveness, medicalisation of home environment: One of the major positives of AAL technologies is their ability to prevent certain harms resulting from the frailty of PwDs (i.e. accidental falls) (Hofmann, 2012; Sponselee et al., 2008). This can have the positive benefit of reducing anxiety (Hofmann, 2012). However, Kosta, Pitkänen, et al. (2010) emphasise the fear about the laboratorisation of the home, which is supported by van Hoof et al. (2011) and Landau and Werner (2012), when they use the expression the 'medicalization of home'. The pervasiveness of AAL technologies poses certain challenges to user privacy, due to the sometimes intrusive nature of these ICT devices. Technologies with privacy-preserving video-sensing are also being developed (Belbachir et al., 2010). These technologies, following the principles of privacy-by-design (Ahonen et al., 2010; Batchelor et al., 2012; Cavoukian et al., 2010; Friedewald and Raabe, 2011; Kosta, Pitkänen, et al., 2010), do not infringe on privacy during their use (for example, due to strong data encryption on the physical layer (Chan, Estève, et al., 2008) or because they are based on wearable technologies (Piasek et al., 2013)).

\subsubsection{Clinical Application}

Ageing at home, autonomy, and dependence on a system: Almost every publication we encountered in our analysis of the field emphasises the benefits of ageing at home instead of institutionalisation: inter alia more privacy, personal integrity, dignity and a positive impact on the self-image (Harrefors et al., 2012; Kosta, Pitkänen, et al., 2010). However, certain authors are sceptical whether the actual autonomy of the PwD is really 
increased through AAL technologies. Enhanced dependence on ICT might result in greater inactivity, promoting a lazy lifestyle instead of a true and desirable independence (Portet et al., 2011; Maguire et al., 2011). Moreover, dependence on technology requires us to put a certain amount of trust (Kosta, Pitkanen, et al., 2008; Kosta, Pitkänen, et al., 2010) and confidence in these systems, despite potential problems e.g. regular false alarm warnings, incorrect notifications or even failures of the technology (van Hoof et al., 2011). Portet et al. (2011) report a certain fear that growing user dependence on AAL technology could expose them to danger in the case of emergency (i.e. if the technology were to breakdown). For example: an automated bed that deflated during a blackout hindered communication with the external world (van Hoof et al., 2011). In addition, sensors, battery-driven devices, and external devices should avoid causing problems for the mobility of users (Darwish and Hassanien, 2011), either when worn or when installed in their homes.

Embarrassment, stigmatisation, social isolation: Ageing at home could have a positive impact on PwD, especially when counter-balancing the negative aspects of institutionalisation (especially in the case of couples, who are used to living together and have done so autonomously and privately for decades (van Hoof et al., 2011)). However, the use of assistive technology or leakage of disease data - associated with the diagnosis of dementia - may cause embarrassment (Kumar and Lee, 2011) or even stigmatisation (Chan, Campo, et al., 2009; Dishman and Carrillo, 2007; van Hoof et al., 2011; Kleinberger et al., 2007; Martin et al., 2010; O’Neill, Mason, et al., 2011; Oppenauer et al., 2007; Palm, 2012; Louise Robinson et al., 2009; Salces et al., 2006; A. Sixsmith and J. Sixsmith, 2008; Sponselee et al., 2008; Wright, 2011; Wright and Wadhwa, 2010; Zwijsen et al., 2010). Some AAL technologies evoked resistance in certain persons with MCI because of their 'handicapped-look' design (Francis et al., 2009) so the design of the devices should be aesthetically pleasing for the users (Francis et al., 2009; Louise Robinson et al., 2009). Fairclough (2009) warns that an explicit feedback of information of a delicate nature coming from an assistive device in front of others or in public spaces can be embarrassing for its user. Stigmatisation can have major effects on the isolation of the user (Kosta, Pitkänen, et al., 2010; Portet et al., 2011; Salces et al., 2006; Sorell and Draper, 2012; Zwijsen et al., 2010), which can be followed by ghettoization (Camarinha-Matos and Afsarmanesh, 2011) or victimization (McLean, 2011) of the user.

Monitoring, surveillance: AAL technologies raise security issues due to risks of surveillance (Kosta, Pitkanen, et al., 2008; Kosta, Pitkänen, et al., 2010), when monitoring of the activities of daily living (ADL) of PwDs. Hofmann (2012), discussing surveillance during the beneficial use of monitoring, questions whether it is possible to define a standard of normal daily activities that can be used in relation to welfare technologies. The heterogeneity of the PwD cohort (Gaul and Ziefle, 2009; Grönvall and Kyng, 2012; Kaye, 2010; Lynch et al., 2009; Mordini et al., 2009; Oppenauer et al., 2007; Remmers, 2010; Salces et al., 2006) greatly complicates the differentiation between normal and abnormal ADL. Moreover, it is unclear who should define normal and abnormal ADL (Hofmann, 2012).

Social exclusion, digital divide, familiarity with ICT, affordability: Kosta, Pitkanen, et al. (2008) and Kosta, Pitkänen, et al. (2010) ask whether the use of AAL technologies 
promotes social exclusion, rather than inclusion. Francis et al. (2009) demonstrate this issue using an example: the use of technology for persons with autism/Asperger's syndrome enables them to communicate better, thus seemingly promoting their social inclusion; however it can actually enforce their social exclusion and cause more intense anxiety by increasing their interactions with others.

The relevant literature also lists another form of social exclusion that is caused by technology, between users of ICT and non-users, namely the digital divide. The digital divide, according to Francis et al. (2009), has arguably similar effects on stakeholders as those of exclusion from ICT design cycles. The digital divide, as a form of social discrimination (Hofmann, 2012), drives society to elitism (Kosta, Pitkanen, et al., 2008; Kosta, Pitkänen, et al., 2010; Satava, 2003). ICT devices can also widen the digital divide (Wright and Wadhwa, 2010) and any existing divisions for example, between the quality of care (Walsh and Callan, 2011) of those already familiar and those unfamiliar with ICT. Batchelor et al. (2012) differentiate younger and older generations based on familiarity with ICT devices, characterising them as 'digital natives' and 'digital immigrants'.

Francis et al. (2009) and Hofmann (2012) both mention that the prevalence of technology for certain people can cause feelings of alienation. Whilst Katz and Rice characterise the role of communication technology as primarily interaction, this interaction can be negative, for example where people cheat, exploit or hurt each other (Francis et al., 2009). Therefore, education and training from an early age on how to properly use ICT should be emphasised, enhancing the motivation to use, familiarity with and overall acceptance of, the ICT systems (McLean, 2011; Mordini et al., 2009; Oppenauer et al., 2007). This could help address the aforementioned issue of digital divide and social isolation.

Wright and Wadhwa (2010) point out that eInclusion (digital inclusion of a person) might not be beneficial to everybody and that there will be certain social groups who will self-willingly exclude themselves from ICT technologies. The group of people classed as 'lapsed users' despite their familiarity with ICT, lack genuine interest in computers (Wright and Wadhwa, 2010).

Other issues for the user, closely related to social discrimination and digital divide, are the overall affordability (Niemelä et al., 2007; Satava, 2003; Wright and Wadhwa, 2010; Zaad and Ben Allouch, 2008; Zwijsen et al., 2010), feasibility (Kosta, Pitkänen, et al., 2010), or cost (Daniel et al., 2009; Zaad and Ben Allouch, 2008) of ICT systems. Economic barriers can lead to isolation too (Abascal and Nicolle, 2005).

\subsection{Formal and informal care-givers (nurses, family proxies)}

\subsubsection{R\&D}

Whose benefit?: The basic interest for care-givers in the development of AAL technologies lies in the possibility of continuous monitoring of PwDs (Darwish and Hassanien, 2011). An important question here is whether AAL technologies mainly benefit the PwD or the care-givers (Hofmann, 2012). Hofmann (2012) points out that whilst many papers mention benefits of welfare technologies, there is a lack of empirical evidence from documented studies substantiating these claims. 


\subsubsection{Clinical Trials}

Data collection: According to Fairclough (2009), during clinical trials, the care-givers, together with the PwD, have the right to know what data are collected about them; the right to access the data if required; the right to provide/refuse their implicit/explicit prior consent; and finally, the right to some benefit for permitting data collection.

Prevalence of technological rationality in human care: Several scholars are sceptical of AAL technologies because of their ability to replace human proximity and care (Hofmann, 2012; R. Sparrow and L. Sparrow, 2006). Moreover, there are reports of concerns regarding the deception of vulnerable people by the substitution of human emotions or relations by technologies (Oost and Reed, 2011) and insecurity (Sponselee et al., 2008) during the use of technology by the care-givers.

Hofmann (2012) questions whether all the stakeholders of the AAL technologies are ready to translate the technologies of hospitals into the home (and private) environments. A home has a special symbolic meaning as a place of confidence, trust, comfort, safety and privacy (Dekkers, 2009), meanings which can be disrupted by hospital technology. Hofmann (2012) also questions the prevalence of technological rationality in the care provided because it might reduce the potential to support and enhance patients' agency.

\subsubsection{Clinical Application}

Instrumentalisation of care, the value of human care: Care-givers, especially proxies, tend to welcome allowing PwD to remain at home, e.g. helping couples to live their lives together for longer at home, even with a moderate-dementia diagnosis instead of the institutionalisation of these persons. However, Hofmann (2012) reports that caregivers are increasingly concerned about the ethical responsibility and legal liability for any possible misuse of the technology in the home setting. He also stresses the possible risks of using ICT, which by its nature emphasises instrumental values, such as productivity and efficiency instead of important relational aspects of human welfare. This criticism is based on the assumption that values such as hope, coping, vulnerability, dignity, meaningfulness or proximity, which are essential core aspects of the human care-giving activity, cannot yet be meaningfully replaced with technologies (Hofmann, 2012). The person-to-person interaction is emphasised as very important (Walsh and Callan, 2011) as opposed to the drives towards replacement of human care with ICT devices (Borenstein and Pearson, 2010; Coeckelbergh, 2010; Oost and Reed, 2011; Portet et al., 2011; R. Sparrow and L. Sparrow, 2006; Vallor, 2011).

Vallor (2011) expresses her concerns about the lack of academic discussion on the question of value of care-giving for care-givers themselves. Whilst being aware of the strenuous work during care-giving, she points out that in most of the literature about assistive technologies (or as she calls them 'carebots'), the practice of care-giving per se is usually suggested as "nothing except a burden" (Vallor, 2011, p. 255). According to her, emotional and social support is considered as a 'task' (R. Sparrow and L. Sparrow, 2006), or care-giving as simply a 'burden', which technologies can help reduce (Borenstein and Pearson, 2010). Stip and Rialle (2005) mention the threat that artificial intelligence poses in replacing the physician/care-giver by a pure data-manager of a database, transforming the notion of patient to a disembodied and virtualised user that 
is manageable from a distance. A. Sharkey and N. Sharkey (2012) highlight the danger of objectification of the elderly by the care-givers via technology (Vallor, 2011).

Overprotection, paternalism, previous work habits, rigid application of protocols: Although care-givers are known for their general protective character and for trying to protect the remaining privacy of the elderly (Sponselee et al., 2008), cases of overprotection by care-givers have been reported (L. Robinson et al., 2007), which could be understood as a form of paternalism (Martin et al., 2010).

Moreover, the literature emphasises the needs of users, which are not always in accordance with the needs of care-givers. This is often the case when care-givers are reluctant to use ICT devices in human care and stick to their previous work habits, irrespective of the needs of the care receivers (Sponselee et al., 2008). Where the application of assistive devices is utilised, the prescribed protocols are reportedly often rigidly followed by care-givers, regardless the needs or requests of the user (e.g. patient lifts, etc.) (Sponselee et al., 2008).

Not-invented-here syndrome: In care-giving institutions a 'not-invented-here syndrome' has been noticed, which means that the formal care-givers tend to be less willing to adopt an AAL system, which was developed outside their care-giving institution or was not solely designed for care purposes only (Sponselee et al., 2008).

\subsection{Researchers and Clinicians}

\subsubsection{R\&D}

Motives for participation in research, eagerness to please, power-relationship between the researcher and PwD: Elderly persons reported various attitudes and motives as reasons for taking part in research: a wish to contribute to the development of AAL technologies, a feeling of obligation to participate in research that could result in progress in the field of study, feelings of curiosity and loneliness, and a desire to find somebody willing to listen (Grönvall and Kyng, 2012).

During R\&D and clinical trials, users tended to be eager to please the researchers or feared offending them somehow (Wallace et al., 2010) or of 'causing some problem by doing something wrong' (Oberzaucher et al., 2009). They often blamed themselves for causing problems (Wallace et al., 2010).

Moreover the physicians' / researchers' relationship to a (vulnerable) user could be a power relationship. The elderly tend to have less confidence in their own judgement (Wallace et al., 2010) and regard researchers as people with higher status and expertise (Maier and Kempter, 2009). Therefore, they tend to defer to their opinion and ideas. According to Maier and Kempter (2009), such power inequalities can negatively affect the whole R\&D process and its results. In cases like this, the elderly person should be reassured that the researchers are performing the research in order that they may learn from them (Maier and Kempter, 2009).

\subsubsection{Clinical Trials}

Meaningfulness and prioritisation of data: Despite the physicians' declared lack of motivation to learn how to use new ICT technologies (Sponselee et al., 2008), the interest that 
clinicians and medical researchers take in AAL technologies partially overlaps with that of the care-givers in the continuous monitoring of the PwD. During the clinical trials, an important aspect for medical researchers is the meaningfulness of the data gathered, both from a scientific and a medical point of view, in order to be able to translate it into valid knowledge (Allen et al., 2008; Conley et al., 2008; Cook et al., 2009; Darwish and Hassanien, 2011; Kang et al., 2010; Kaye, 2010; Noury et al., 2011; Romdhane et al., 2012; Viswanathan et al., 2012; Wherton and Monk, 2008). The accuracy and reliability of such data has to be prioritised, according to their relevance, importance and urgency (Darwish and Hassanien, 2011; Viswanathan et al., 2012).

Safety and security of PwD: With various technologies and their functions (location tracking, drug intake monitoring, social interaction detection, etc.), the reduction of fear and insecurity amongst the elderly has been documented, as well as an increase in both, genuine and perceived safety (Hofmann, 2012; S. Lauriks et al., 2007).

\subsubsection{Clinical Application}

Human-centred approach: The clinical application of AAL technologies should incorporate two considerations with regard to a human-centred approach. Firstly, a human-centred computing approach should consider the health- and technology-orientation of an ambient system, along with the need for comfort of the PwDs (i.e. their special needs as persons; the need for empowerment living in their homes; etc.) (Portet et al., 2011; Zaad and Ben Allouch, 2008). Secondly, a consideration of whether the need for AAL technologies is in the best interest of the individual PwD (Scanaill et al., 2006). The aforementioned considerations pose decision-making challenges linked with the responsibilities and competencies of both the clinical researchers and clinicians (Hofmann, 2012).

Allocation of resources: Duquenoy (2004) stresses the question of who decides about the prioritisation of information, bandwidth, machine power, storage and, more generally, the allocation of resources and trade-offs.

ICT and diagnosis, automated machine diagnosis: The use of ICT devices in healthcare is divided between the services- and information-related forms of telehealth (tele-care and tele-rehabilitation) for end-users, and telemedicine, which is defined by Plaza et al. as ICT devices used for diagnosis (Plaza et al., 2011). Behind the introduction of ICT into the arena of healthcare is the shift from the traditional reactive approach, namely diagnosis and treatment or cure, towards the preventive approach, namely, monitoring and early detection of diseases (Palm, 2012). Regarding PwDs, the focus in diagnosis is on the preclinical state, when the symptoms provide enough variances during monitoring to enable the projection of the possible later loss of independence and physical functioning (Merilahti et al., 2012). The role of ICT in diagnosis is to predict and track the progression of the disease (Dishman and Carrillo, 2007), often doing so remotely (Hofmann, 2012).

The automated diagnosis via ICT technology is welcomed by a few authors (Camarinha-Matos and Afsarmanesh, 2011; Darwish and Hassanien, 2011; Friedewald and Raabe, 2011). In addition to the current difficulties with fidelity and trustworthiness of such systems (Fairclough, 2009; Gaul and Ziefle, 2009; Kleinberger et al., 2007), there 
are also legal constraints. In the context of EU laws, persons have a right not to be subjected to significant decisions based on any such automated processing (European Commission Data Protection Directive 95/46/EC) (Kosta, Pitkanen, et al., 2008; Kosta, Pitkänen, et al., 2010). Similar regulation is present in Japan's Doctor's Act no. 20, which prescribes that diagnosis should be provided only by direct examination of a patient, not by a machine (Chan, Estève, et al., 2008).

\section{4 (Software/Hardware) Engineers}

\subsubsection{R\&D}

User-involvement in RED: It may be detrimental if engineers and designers of AAL technologies do not involve persons with dementia in the customisation and co-design of these assistive technologies (Francis et al., 2009; Gaul and Ziefle, 2009).

Security of medical and personal data: A significant number of articles raise concerns about security (see Figure 4), which in the case of medical and personal data necessitates the provision of strong data security, even automatic encryption (e.g. encryption in the physical layer) (Chan, Estève, et al., 2008). The encryption of personal data is stipulated by both international and national legislation (for example: Title 21 of Code of Federal Regulation (CFR) Part 11; or Data Protection Directive 95/46/EC). Kumar and Lee (2011) stresses the importance of protection against Denial of Service (DoS) attacks on the whole system because of their potentially tragic consequences. Moreover, the Quality of Service should be evaluated together with the security of the system (Kumar and Lee, 2011).

Safety of the AAL system: The installation of assistive technologies, as previously mentioned, should not reduce the mobility of their users (Darwish and Hassanien, 2011). This also holds true for implantable (in vivo) sensors (Chan, Estève, et al., 2008). These should also not overheat or harm their user (Darwish and Hassanien, 2011).

Tasks not suitable for ICT: During the R\&D, according to Hofmann (2012), engineers should be aware of, or be warned by other stakeholders about certain tasks, which are not suitable for ICT solutions. R. Sparrow and L. Sparrow (2006) point out that, in future, different types of assistive robots are supposed to provide either physical services, such as lifting, turning, monitoring; or caring and emotional labour, such as conversations, social interactions, sympathy, emotional support, etc. By introducing these solutions, we may also be withdrawing the only regular human social contact for the elderly, namely the people providing physical care for them (professional care-givers, cleaners, household maintenance assistants, etc.) (R. Sparrow and L. Sparrow, 2006). R. Sparrow and L. Sparrow (2006) therefore emphasise that the human companionship provided by care-givers is at least as important as the physical duties they perform.

Technical or 'quick' fix, RED for PwDs as low prestige endeavour: The danger of regarding AAL technologies as 'quick and easy fixes' or a 'technical fix' to grave psycho-social and societal problems is still present (Hofmann, 2012; Mordini et al., 2009). Moreover, researchers see the development of technologies for the elderly as a low-prestige endeavour (Hofmann, 2012) (compared with other technologies, e.g. diabetic insulin pumps, 
artificial cardiac pacemakers, wearable EEG systems, or wearable dialysis machines, etc.), although the need for these technologies is increasing.

Mismatched expectations of users and engineers: The literature warns about mismatched expectations of engineers/researchers and actual users of a system (Allen et al., 2008). For example, video-telephony is often understood as enhancing the social inclusion of a user but according to van Hoof's empirical study, it did not always reduce feelings of loneliness or improve the social contacts of the users (van Hoof et al., 2011). Therefore, an analysis of the broader social context is required (Duquenoy and Whitehouse, 2006; Duquenoy, 2004).

Interoperability and compatibility of systems: During R\&D the longevity of AAL technologies requires that they must be developed with the possibility of extending and integrating their use with other future systems and sensors (Chan, Estève, et al., 2008; Darwish and Hassanien, 2011; Román et al., 2009).

Special status of human experimentation: The engineers should be aware of the dangers and issues linked with human experimentation (Mordini et al., 2009).

\subsubsection{Clinical Trials}

Indispensable third parties: The responsibilities of indispensable third parties, without any direct health responsibilities (electricity-, heating-, gas-providers, technical service, etc. (Hofmann, 2012; van Hoof et al., 2011)) for the application of assistive technologies in home environments, must be considered critically from the clinical trials stage onwards. An unexpected power-cut or loss of internet connection by an Internet service provider could have tragic consequences in a smart home and for a PwD using wearable life- and health-logging sensors. Furthermore, privacy and confidentiality could be infringed (Hofmann, 2012). The question at stake is the allocation of the responsibility.

Kosta, Pitkänen, et al. (2010) express that the liabilities can be strict, meaning that if, for example, from the clinical trials stage onwards, an unauthorised person gains access to sensitive data, the controller should be held responsible for the damage regardless of culpability. This view of liability could be applied to the indispensable third parties as well.

Wright mentions the notion of 'overlapping responsibilities' (Wright, 2011, p. 211), originally defined by Vedder and Custers (Wright, 2011). In the development of new technologies the stakeholders at various stages of the development have only limited insight into the opportunities and risks involved, while at the same time having only very limited means to respond. As it is undesirable to assign all the responsibilities of a highly complex system to only one group of stakeholders, overlapping responsibilities are favourable in cases when there is usually a responsibility gap (Wright, 2011).

Finally, Decker (2012) calls for legal accountability of damages caused by service robots themselves. In principle, the owner of a service robot is liable for the damages caused only if he or those assisting him are personally responsible. Mistakes in the production or instructions of a product are the responsibilities of the manufacturer (Decker, 2012). However, the liability of the owner is again questionable, if such a robot adapts autonomously to various situations, or can react to human beings, other robots or the environment. Therefore, its behaviour is not predictable in detail. Decker et al. 
(2011) ask whether, for such cases, an independent legal 'liability' and new rules of accountability should be called for.

Testing of AAL technologies: Hofmann (2012) further expresses the need for more intensive testing of AAL technologies. Compared with the testing of drugs in healthcare, the regulation of ambient technologies seems to be lax (Hofmann, 2012). Portet et al. (2011) clarify that in principle, there are three possible venues of testing: a) in situ (in the real environment of the user), b) in vitro (in laboratories), and c) in-sitro/in-simu (in a simulated environment, reproducing the users' home environment). Against this background, Portet et al. (2011) point out that there are very few instances of in-situ testing. He also remarks that although the in vitro tests are more affordable and possibly more objective, the in situ tests provide more realistic data, although at a higher cost and possibly with an observers' subjective bias. The in-sitro/in-simu experiments are able to identify most of the usability problems found in other conditions, though not as precisely as the in-situ experiments, hence in-sitro /in-simu experiments are particularly suitable for prototyping (Portet et al., 2011).

\subsubsection{Clinical Application}

Data safety and protection: During clinical application, demand is placed on the engineers to deal with the issue of data protection (Kosta, Pitkanen, et al., 2008), involving its secure storage for a requisite amount of time, and its subsequent secure removal (Abascal and Azevedo, 2007). Duquenoy (2004) emphasises that the bandwidth, processing power, memory, etc. necessary for transferring and processing medical data is a scarce resource and therefore, an adaptive and on-going negotiation about operational space and its prioritisation should be applied.

Principle of proportionality: Hofmann (2012) indicates that the proportionality principle, should be applied during the application of welfare technology, ${ }^{7}$ especially surveillance technologies. Accordingly, the harm and burden caused must be appropriate in relation to the benefits yielded. For example, a tracking system should not impose physical restrictions or mobility surveillance on its user by limiting his or her activities but rather, should apply less obtrusive subjective barriers, with labels, mirror doors, $\mathrm{RF}^{8}$-coded access points, etc. However, the benefit of these alternatives could also be questioned (Hofmann, 2012).

Easy to learn, error free ICT: Assistive technology should be easy to learn for future users. Also, it should be as error-free as possible (Portet et al., 2011).

Different life-cycle of technology and service, technology push: The engineers of ambient assisted solutions should bear in mind the differences between the life-cycle of a device (technology), and the life-cycle of the healthcare service providing it, as they are usually not identical. The health service begins with the person going to see the clinician, and it

\footnotetext{
${ }^{7}$ Hofmann defines welfare technology as a heterogeneous group of technologies which are "supposed to give better and more focused care, reduced risk and increased safety, increased coping and selfdetermination, make it possible to stay at home longer, avoid harm (from falling, fire, robbery), make more just resource allocation, and to promote technology development, commercialization and growth." (Hofmann, 2012, p. 391)

${ }^{8}$ Radio-frequency
} 
ends when the clinician resolves the person's problem. The technological life-cycle is different: it is developed, produced in large quantities, and distributed to selling points. From an ethical point of view, a service life-cycle is more human-centric, while that of a product is more technology-centric. According to Kosta, Pitkanen, et al. (2008) and Kosta, Pitkänen, et al. (2010) the former should be highlighted. Furthermore, because the difference between life-cycles is not clear, how much ethical analysis is transposable from earlier product study, and how much new ethical analysis is required in a new model of ambient intelligence (Kosta, Pitkänen, et al., 2010) is an open question. Related to this, Chan, Campo, et al. (2009) point out that the technology push from the industry is usually greater than the demand pull from the users' needs, which can cause user disappointment.

The role of AAL technologies: Rapoport (2012) notices that the role of ICT devices regarding the human body facilitates a new perception of the body itself: mediated through technologies. Moreover, beyond merely detecting, the technologies do currently also take on agency, make choices, assume the intentionality allotted to human beings while performing actions in a purposeful, goal-oriented manner. Such a technology thus turns into a proxy (Rapoport, 2012).

\subsection{Designers}

\subsubsection{R\&D}

Design-for-all approach and heteronomous group of PwD: For the designers, the literature emphasises the user-centred approach to design (Wallace et al., 2010), which means a universal design for users with various needs and requirements. The design-for-all, universal design, and inclusive design approaches are characterised by encouragement of designers to extend their designs to include older and disabled people in all phases of R\&D (Newell et al., 2011), despite the higher cost, extra work (Abascal and Azevedo, 2007; Sponselee et al., 2008) and greater attention required from the designers (Wallace et al., 2010). However, according to Portet et al. (2011), the design-for-all approach may be inappropriate for PwD because of their specific individual needs and pathologies. He emphasises that "no smart home application is going to be successful if the intended users are not included in the design" (Portet et al., 2011, p. 132). It is imperative to focus on safety design - privacy and security by design (Kosta, Pitkanen, et al., 2008; Kosta, Pitkänen, et al., 2010), which maintains privacy (Portet et al., 2011) and user-friendliness (Darwish and Hassanien, 2011; Duquenoy and Whitehouse, 2006).

User involvement in $R \mathcal{E} D$ : As stated before, the active involvement of users in the process of design is necessary for the overall usability and success of AAL technologies (as is the case with the user-centred Participatory Design Approach during the design of disability assistive technology for people with autism/Asperger's syndrome (Francis et al., 2009)). This approach could also be referred to as 'proactive design' (Duquenoy, 2004), as a holistic approach or perspective (Kosta, Pitkänen, et al., 2010), as value sensitive design (Wright, 2011), ergonomic design (Wallace et al., 2010), or simply as ethical design (Kosta, Pitkanen, et al., 2008). The involvement of (vulnerable) users in the design process can be maintained by means such as role-playing (Picking et al., 
2012), drama (Sponselee et al., 2008) or acted performance (Newell et al., 2011), and interviews (Maier and Kempter, 2009).

The feedback from users for design is crucial because every target user is a domain expert (Allen et al., 2008). Borenstein and Pearson (2010), quoting Oosterlaken, emphasises that the details of design are morally significant. Details such as a step-by-step design (Aarts et al., 2007; Burleson et al., 2012; Pulli et al., 2012), or large and coloured buttons (O'Neill, Parente, et al., 2011; Picking et al., 2012), and the overall intuitiveness (Maguire et al., 2011) of a system are preferred if these are helpful for the end-users. The reported difficulties of elderly users of ICT are usually about hardware issues, inconsistent interface, screen size, height mobility, information interpretation or the overall mental (rather complex) model applied (Lorenzen-Huber et al., 2011; Wallace et al., 2010). Hersh et al. (2003) would also welcome financial payments for users providing feedback.

Definition of disability: Since the development of the classic functional model by Nagi in 1965 (Lynch et al., 2009), the design-for-all approach tries to address the paradigm shift from understanding disability solely from a medical perspective to understanding disability in a social context. In this approach, the biological and pathological characteristics of the impaired individual are less important compared with the social context (functional limitations and disability) (Appleyard, 2005; Darzentas and Miesenberger, 2005; Lynch et al., 2009).

According to Abascal and Nicolle (2005), instead of being rigid, the design should be adaptive, dynamically adjusting itself to the needs of its user, and consequently reducing potential user's anxiety. Bad design facilitates more handicaps through less accessible systems (Abascal and Nicolle, 2005).

Relationship of designers with PwD: As the care-givers could be technophobic (Sponselee et al., 2008), the designers are in general the opposite, technophiles (Wallace et al., 2010). In addition, the age gap between PwD and designers can be an issue (Wallace et al., 2010), triggering communication difficulties in introducing ICT (Sponselee et al., 2008). The power relationship, between the (formal) care-givers/researchers and the PwDs is, as mentioned above, possible between the PwD and designers as well (eagerness to please (Francis et al., 2009), deferring to the opinion of the researcher as a person with higher status and competence (Maier and Kempter, 2009), etc.). Hence, the use of focus groups, where the users share their ideas with the researchers/designers in an interactive, open, and friendly manner, is welcomed in most of the literature (Brown et al., 2004; Brown et al., 2006; Maier and Kempter, 2009; Walsh and Callan, 2011). Wallace et al. (2010), however, find focus groups unsuitable due to efforts to utilise as many participants as possible, resulting in less useful discussion.

\subsubsection{Clinical Trials}

Testing, impact assessment: Although some untested systems could be reportedly beneficial for the users (Steve Lauriks et al., 2010), as already mentioned, very little in situ testing was reported by Portet et al. (2011), with a lack of more general socio-economic impact studies (Chan, Estève, et al., 2008), and a lack of studies of gender differences (Chan, Campo, et al., 2009). Cahill et al. (2007) emphasises that pre-testing in the care 
of PwD is critical to ensure the reliability and efficiency of the devices. According to Scanaill et al. (2006), very few impact assessment methodologies were developed and a relatively small number of them are able to enforce actions based on their results. Wright (2011) proposes a framework (ethical principles, values, issues, and questions) for impact assessment to ensure that responsibilities and considerations of the designers regarding technology are ethically adequate and not detrimental to the generally accepted social values.

\subsection{Technicians}

\subsubsection{Clinical Trials}

Sensitive installation of devices: Technicians are the mediators between the technology, the PwD, and their homes. Their approach to the installation and removal of the technological equipment must be very sensitive, in order to avoid producing extra harm and anxiety for the PwD. Van Hoof et al. (2011) mention the complaint of one of the participants of their research about the drill-holes left behind by technicians in their home. Also, research participants may be worried about the presence of 'strangers' in their home environment (van Hoof et al., 2011).

\subsubsection{Clinical Application}

Naturally, the remark above about sensitivity holds for the application stage as well. Furthermore, during a regular maintenance/check-up activity, technicians should consider the special status of PwD, for example by minimizing repeated departure-and-returns to the easily confused patient's home during a single session. Due to the possible memory impairment of the PwD, technicians should work in pairs, in order to maintain a constant presence and connection with the PwD residents and to avoid losing touch with the PwD. They should also be able to listen and repeatedly explain their activities to the PwD and answer their questions (van Hoof et al., 2011). In this case, the indispensable third parties demand special attention because their staff may have different (technology) competencies (van Hoof et al., 2011), and could also have very little experience of working in health care.

\section{Discussion}

In the current scholarly debate as identified in our study of the literature reported in the previous section, privacy, safety and security issues are major concerns in relation to AAL technologies for PwDs. It is also clear, however, that PwDs have persistent mobility issues and need support for their everyday living at home, which can be provided by AAL technologies. In addition to these issues, we wish to highlight the following ethical aspects that have not received enough attention yet in the scholarly debate: 1) value of the goals of AAL technologies, 2) the special vulnerability of PwDs in their private homes, and 3) informed consent. 


\subsection{Value of the goals of AAL technologies}

Here we consider whether the a) motives for the development and b) the ambitious goals promised by the AAL technologies are really valuable. Our focus on the value of the goals in this section will be exclusive. We will omit the assessment of the feasibility of the goals of AAL technologies because such an assessment is subsidiary to an assessment of the value of the goals, and does not focus solely on the ethical aspects.

Many of the articles we reviewed accept the benefits of using AAL technologies (e.g. better care, 24-hour non-stop care, staying at home longer for $\mathrm{PwD}$, cheaper option than a nursing home, maintenance of independence and autonomy of PwD, etc.). Very few articles critically question this presumption.

Firstly, one should consider the question of who will primarily benefit from the application of AAL technologies. Hofmann (2012) predicts that the use of assistive technologies (which he calls 'welfare technologies') will benefit the care-givers more than those in need of care. This criticism raises serious questions about the justification of using AAL technologies for PwD, as it might turn out that the biggest share of benefits are for third parties, whilst those most in need of care bear the brunt in terms of risks and harms from their use. Therefore, the motivation of the R\&D of AAL technologies has to be clearly stated because different ethical considerations apply, particularly if such a system benefits the care-givers more than those in need of the care.

Secondly, regarding the issue of motives for developing AAL technologies, Sorell and Draper (2012) stress the fact that by definition, AAL technologies set as their main priority, the provision of independent living and staying longer at home (as Sponselee et al. (2008) call it: 'extramuralization') for persons with chronic diseases. The policy changes in the UK for telecare serve as an example of the cutting back of institutionalisations and the shortening of hospital stays, indicating that the goals of ambient intelligence can align with governmental policy. However, Sorell and Draper (2012) note that although this policy coincides with the motivations of the elderly, this does not mean that the governmental motivations are the same as those of the elderly and not solely economic. Using an economic angle for policy, telecare (including ambient intelligence, AAL technologies) maximises self-financing. In the light of telecare having a cost-cutting effect, the presentation of it solely as a means for prolonging independent living may be disingenuous. Similarly, although increasing the default retirement age has a cost-cutting effect on pension benefits, this governmental policy is often presented with the rhetoric of an anti-ageist approach (Sorell and Draper, 2012). Hence the motivation for cost-cutting has to be carefully assessed. We agree with the finding of Holzinger et al. (2008) that the benefits of using technology in the arena of healthcare (including care of PwDs) must be clearly appreciable, either on physical, medical or emotional grounds. The recognition of these values provides not only acceptance from its users but also motivation and justification for its research (Holzinger et al., 2008).

The varied pathologies linked with dementia are currently the objects of scientific research, which investigates their biological nature as well other (phenomenological, behavioural, etc.) aspects. Consequently, one of the goals of the development of AAL technologies, from a medical point of view, is the recording of health-related scientific information. The collection of data in-situ, i.e. within the home-settings of the PwD, is very challenging for researchers. In addition, the presence and intrusive nature of 
the AAL technologies in the home environment of a PwD, with their possibly harmful effects, raises serious ethical issues (surveillance and continuous monitoring, pervasive nature of the technology, data safety, etc.). That being said, it might open up the horizons for establishing better scientific foundations for more sensitive diagnosis and treatment or management of dementia. The perspective of better diagnostic techniques could be a valid justification for the introduction of AAL technologies to PwDs. However, this benefit, as such, may be too small to justify the serious potential harms and risks thus posed to this very vulnerable segment of the population. Similarly, the application of sensor-systems, mainly for research data collection could also go against the proportionality principle.

Let us look at an example: One of the major fears of PwDs is falling, as reported by Hofmann (2012) and van Hoof et al. (2011). However, even the most advanced and complex ambient technology would be undesirable, if the benefit could also be provided by a more lightweight, simpler, cheaper and easier-to-use system. Currently, despite the immense efforts of research in the area of AAL technologies, the smart-home full of sensors does not provide greater help in preventing or assuaging the fear, not to mention coping with the situation of a PwD falling than a much simpler one-button, danger-reporting alarm worn around the neck. Ambient intelligence should provide much more benefit than being just another solution for reporting complications for PwDs. The obtrusiveness of ambient intelligence demands proportional benefits in the well-being of their actual users.

In addition to the issue of proportionality, Hofmann (2012) asks who will define, and on what basis, what constitutes the average everyday normal activity for a PwD under the control of surveillance technology? As mentioned before, the cohort of the elderly, including PwDs is a heterogeneous group (Gaul and Ziefle, 2009; Grönvall and Kyng, 2012; Kaye, 2010; Lynch et al., 2009; Mordini et al., 2009; Oppenauer et al., 2007; Remmers, 2010; Salces et al., 2006). Different users have different needs, behavioural expressions and habits. Therefore, the goals of AAL technologies should be defined alongside the provision of a high level of customisation and adaptability of the system to the activities and needs of every individual user. Introducing an AAL system to a private home should avoid forcing users into performing activities, which are considered to be unpleasant and burdensome, and are required solely by the introduction of assistive technologies into the healthcare process. For example: users reported problems with false alarms, which are, because of the sensitivity of the ambient technology, somehow inevitable (van Hoof et al., 2011). AAL technologies should not give the PwD unreasonable extra burden of taking care and managing the technology. The aim of AAL technologies is to provide support and empowerment and a feeling of safety and security, not the burden of performing extra tasks. Researchers cannot expect that a person with MCI and with fading memory capabilities will defer to the requirements of a system, which is not intuitive and easy to use. Such a scenario contravenes the very definition of AAL technologies, which are supposed to disappear into background without any undue need for human interference. Therefore, efforts should be made during R\&D to ensure that the technology fulfils the 'ambient' attribute of its definition. As Abascal et al., quoting Thimbleby, remarked, "badly designed systems handicap all users" (Abascal and Nicolle, 2005, p. 491), not only PwDs but also 
care-givers, family members and physicians.

The heterogeneity of the group of PwD includes geographical and cultural differences too. However, there is a dearth of literature regarding the possible labeling of AAL technologies. The development of AAL technologies should, in the future, discard the label of being developed in highly industrialised and computerised Western societies. Therefore, in order to fulfill - globally - the goals of beneficence and value, the variety of culturally influenced characteristics to be found between different countries and cultures, deserve deeper analysis.

Also, when ambient technologies are widely used, the freedom to refuse assistance from AAL technologies has to be considered. It is not known, whether, in the future, compulsory introduction of AAL systems at home could be refused by a PWD, for example if they were offered by her insurance company. Also, it is not known whether a proxy of a PwD would have a right to refuse the deployment of AAL technologies. More empirical research is needed regarding the acceptance, usage and overall personal and social impact of AAL technologies upon their users.

In summary, the value of the goals of AAL technologies is generally positive: according to the literature, they aim to give assistance, support, empowerment, a sense of security to vulnerable persons, and aim to facilitate them staying longer at home whilst maintaining their comfort, social connections and security. However, extra attention should be given to attempts to reduce the possible harms and risks for the vulnerable PwDs. Researchers should bear in mind that the provisioning of AAL technologies for PwDs is non-therapeutic, thus the justification of possible harms involved requires an outweighing amount of benefits to make the assistance of AAL technologies favourable. Still, due to a lack of sufficient empirical evidence, the feasibility of achieving all the beneficial goals of AAL is still very much an open question and requires more research.

\subsection{Special Vulnerability of PwDs in Their Private Homes}

Although modern hospitals and care- and nursing-homes currently use a plenitude of technologies, for which partial responsibilities are held by various stakeholders (engineers, designers, etc.), there is usually a 'safety net' of human care-givers (nurses, clinicians, proxies) present in case of any malfunction of the technology. AAL systems by their nature try to reach a level where such assistance should not be needed, thus enabling users to live at home for longer. Moreover, assistive technologies are not present in clinical settings but rather in the private homes of PwDs. A misunderstanding with technology at home can cause extra harm, instead of providing support for the PwDs, compared with settings in hospitals or nursing homes. These facts introduce a need for a much higher level of safety and reliability in AAL technologies than in technologies used in hospitals and nursing homes.

Furthermore, where the interactivity of AAL technologies is necessary, the system should also provide measures that allow the reporting of false alarms by the users themselves. The cognitive condition should not disqualify PwDs from a certain amount of control, self-determination and evaluation of the applied AAL technology. The seemingly contradictory requirements of AAL technologies, of being ambient and interactive at the same time, necessitate a careful design process and empirical research 
about the needs and habits of the users, while maintaining their safety and security in their preferred environment.

Besides, although debated by some (Decker et al., 2011), it would be ethically unacceptable that in case of fault or malfunction, the responsibility is allotted to the 'system' and not to somebody, who designed, engineered, applied, or (mis)used it. Therefore, there is a serious need for guidelines for the R\&D of the AAL technologies, where the liability and accountability of a developed technology is preserved throughout the whole process of R\&D, trial, application and ensuing continuous use of the AAL technology.

In the R\&D stage, designers should actively involve PwDs as they will be the endusers of the technology. In addition, during the R\&D procedure, a correct balance should be struck between cost-effectiveness on the one hand and the quality of the methodology to obtain feedback from the participants of ambient technologies on the other. Such a balance needs to be emphasised because methodologies to obtain quality feedback (in vitro, in-sitro/in-simu, in situ scenarios) can significantly increase costs. Depending on the costs involved, participant feedback methodologies are differently optimised and can provide different results for the R\&D process (Portet et al., 2011). These differences may be crucial and could cause serious issues later on, during the final introduction of the AAL technologies to a wider group of PwDs. So the quality of the feedback methodology directly affects the quality of the feedback from the PwD participants. Therefore, as the introduction of the PwDs into the R\&D process is vital, the quality of the feedback itself must also be considered as essential for the entire project of the use of ambient intelligence for PwDs.

However, the vulnerability of PwDs imposes serious requirements on the quality and quantity of data collected during the R\&D procedure (how many sensors can a research participant with dementia wear, for how long, how many sensors are necessary to be installed in the in-situ private home environment, etc.). Therefore, judiciousness from the researchers is required in their approach to the PwDs as human beings and at the same time, in their assessment of the quality of data gained from the PwDs as research participants. A more comprehensive human-centred approach from researchers and care-givers can be extremely beneficial for all the stakeholders, especially during the R\&D process. With a human-centred approach, all the processes of introducing and maintaining the AAL technologies could be made more successful by being stress-free and goal-orientated, while also avoiding the dangers of technical/technology-based and economic biases. This will very likely ensure a better applicability of the AAL technology in the final clinical application period.

Hofmann (2012)'s comparison of the complexity and profundity of the testing of pharmacological drugs and their introduction into the healthcare system with the relative lack of rigorous testing and regulation when it comes to medical devices in healthcare is noteworthy. Dishman and Carrillo (2007) find the approach of review boards regarding everyday technologies for AD care ill-equipped and worthy of criticism because their members may be unfamiliar with the technology, and often evaluate the risks of ICT devices on the basis of drug trials, while they involve "little to no participant risk" (Dishman and Carrillo, 2007, p. 232). However, despite the lax regulation for testing medical devices, we are obliged to state that the impaired condition of 
PwDs requires rigorous ethical considerations during research, testing and application periods.

Finally, one of the expressed hopes of researchers is the future use of continuously operating (ambient) machines for diagnostic purposes (Camarinha-Matos and Afsarmanesh, 2011; Darwish and Hassanien, 2011; Dishman and Carrillo, 2007; Friedewald and Raabe, 2011). However, in various countries, such a scenario is already subjected to regulation and is legally prohibited (Beyleveld, 2011; Chan, Estève, et al., 2008; Kosta, Pitkanen, et al., 2008; Kosta, Pitkänen, et al., 2010).

In short, the special vulnerability of PwDs with their declining cognitive abilities should put the researchers on guard regarding the research and testing of AAL technologies on this group of participants. Researchers should also be more alert due to the lack of 'safety nets' in private home environments, which are usually present in hospital and nursing home scenarios.

\subsection{Informed Consent}

Informed consent is considered crucial for the application of any research or treatment with technology in healthcare. The importance of the notion of informed consent has become more apparent since the Nuremberg trials and has accordingly been legally embodied in many modern jurisdictions. Hence, the notion of informed consent has a strong legal dimension. According to the definition of Beauchamp \& Childress, informed consent is an "individual's autonomous authorization of medical intervention or of participation in research" (Beauchamp and Childress, 2009, p. 119).

The present justification of informed consent is based on considerations of autonomy. Not being treated as mere means but always as ends, means that people must have an opportunity to choose to participate in research or to undergo a treatment (Beauchamp and Childress, 2009).

According to Árnason et al. (2011), the modern understanding of valid informed consent consists of three parts: a) competence (ability to do what is needed to perform a task), b) understanding (disclosure of relevant information is a precondition of adequate understanding of the information about a treatment/research), and c) voluntariness (being aware of the possible outcomes).

The logic of competence means that even a healthy person is not globally competent because no one has the ability to do all mental and physical tasks. Therefore, Árnason et al. (2011) propose that competence should be understood as a task-specific notion, rather than a global notion. This task-specificity is based on a person's abilities to understand and perform a particular decision-making task in a particular situation (Árnason et al., 2011).

Regarding understanding, Árnason et al. (2011) stress that no one has a pure and abstract understanding of clinical treatments/research. A professional's duty is to find a correlation between the personal background knowledge of the participant and the information about the treatment/research, in order to reach an adequate level of comprehension of the relevant information. This correlation has to be reached with the usage of comprehensible (plain) language, while the participant is neither overloaded with the information, nor under-informed (Árnason et al., 2011). These principles pose 
challenges to the researchers when requesting informed consent from a PwD with gradually developing MCI or memory impairment.

Finally, a valid informed consent has to be voluntary. This means that in order to be able to make a decision, one has to be aware of the possible relevant outcomes of the research. In addition, informed consent had to be requested while not being under the influence of coercion, deception, persuasion, or manipulation. The assessment of the voluntariness of consent usually is the responsibility of the researcher (Árnason et al., 2011) with oversight from the research ethics committees. As already mentioned, the eagerness to please the researcher or a proxy, higher status and trust in the competence of the researcher, family relationships can influence the voluntariness of consent of the participant negatively. Cultural influences can play a specific role here, since certain cultures prefer to make collective decisions (Árnason et al., 2011). In addition, voluntariness should incorporate the possibility for a participant to opt-out of the research at any time without necessarily giving a reason.

PwDs with MCI and memory issues pose a serious challenge regarding informed consent. The developing MCI and progressive memory and communication issues of the PwD may affect the quality of the aforementioned requirements of informed consent considerably. During the progression of dementia, the task-specificity of competence and the understanding of PwD may change. These require the introduction of a concept of informed consent that is adapted to the altering conditions of PwD, which we call 'rolling informed consent'. Rolling informed consent involves: a) the necessity of repeatedly providing information on an iterative basis (i.e. not only when requested), and also asking for consent during the various stages of the treatment/research, $b$ ) listening to the content and nuances of the speech of PwD and continuously assessing whether her participation is voluntary and not subjected to coercion, persuasion, manipulation, or simple distress, which if so subjected, would be sufficient reason to end the session for the researcher without needing the expressed request of the participant (Astell et al., 2009), while also c) communicating the possibility of opting-out or withdrawing from treatment/research at any given stage. Rolling informed consent in the case of PwD does not result in a single-event legal act but rather, is a continuous consideration of the choices made by the vulnerable person. The need for a concept of rolling informed consent is also supported by Árnason et al. (2011), when they define informed consent, not as a unique (legal) event but rather, as a communicative process between the relevant parties (Árnason et al., 2011). In practice, however, rolling informed consent could cause issues for the care-givers, clinicians, and researchers regarding considerations of its validity and its being time-consuming to obtain. Rolling informed consent might prolong the whole treatment/research process, hence care-givers might see it as an impediment to their work.

The responsibility of the researcher in assessing the changing competence of the PwD during the R\&D increases within the context of rolling informed consent. Such an assessment may be considered very subjective. However, the assessment may be based on the special, often long-standing relationship and bond, which is usually shared between PwDs and their clinicians/researchers. It is not clear whether researchers have a more objective means of assessing the changing competence of PwDs. The development of such a protocol promises to be challenging and worthwhile. 
Despite the difficulties of obtaining informed consent from PwDs, the introduction and application of rolling informed consent is inevitable in the case of PwDs, given the empirical characteristics and progressive nature of dementia, while at the same time taking seriously the participant's autonomy. The principles of respect for the participant's autonomy and respect for potential enrolled subjects are broadly accepted as pivotal ethical requirements in research and healthcare settings, especially when dealing with vulnerable persons (Emanuel, Wendler, and Grady, 2000).

\section{Conclusion}

AAL technologies are said to provide assistance and support to vulnerable persons and those with dementia by allowing them to live for longer at home whilst maintaining their comfort and security. However, the R\&D, clinical trials and the application of AAL technologies also pose serious ethical challenges. The ethical challenges mostly focused on in the literature to date are concerns about safety, security and privacy.

Although these issues are undoubtedly relevant, further ethical issues need to be addressed as well. They involve the value of the goals of AAL technologies, the special vulnerability of PwDs in their private homes, and the complex issue of informed consent from PwDs. These issues urgently need further analysis in order to ensure that $R \& D$, clinical trials and the application of AAL technologies take place only in accordance with the highest ethical standards.

\section{Acknowledgement}

This research has received funding from the European Community's Seventh Framework Programme (FP7/2007-2013) under grant agreement 288199 - Dem@Care.

\section{References}

Aarts, Emile, Panos Markopoulos, and Boris Ruyter (2007). "The Persuasiveness of Ambient Intelligence". In: Security, Privacy, and Trust in Modern Data Management. Ed. by Milan Petković and Willem Jonker. In collab. with Milan Petković and Willem Jonker. Data-Centric Systems and Applications. Springer Berlin Heidelberg, pp. 367-381. ISBN: 978-3-540-69861-6. DOI: 10 .1007/978-3-540-69861-6_24. URL: http: //www. springerlink.com/content/m757771368ug4746/abstract/ (visited on 03/19/2012).

Abascal, Julio and Luis Azevedo (2007). "Fundamentals of Inclusive HCI Design". In: Universal Acess in Human Computer Interaction. Coping with Diversity. Ed. by Constantine Stephanidis. Vol. 4554. Lecture Notes in Computer Science. Springer Berlin / Heidelberg, pp. 3-9. ISBN: 978-3-540-73278-5. URL: http: / / www . springerlink. com/content/92m6253u60350m65/abstract/ (visited on 06/01/2012). 
Abascal, Julio and Colette Nicolle (2005). "Moving towards inclusive design guidelines for socially and ethically aware HCI". In: Interacting with Computers 17 (5), pp. 484505. ISSN: 09535438. DOI: $10.1016 / \mathrm{j}$. intcom. 2005.03 .002 . URL: http: / / linkinghub.elsevier.com/retrieve/pii/s0953543805000226 (visited on $04 / 05 / 2012$ ).

Ahonen, Pasi et al. (2010). "Safeguards". In: Safeguards in a World of Ambient Intelligence. Ed. by David Wright et al. In collab. with David Wright et al. Vol. 1. The International Library of Ethics, Law and Technology. Springer Netherlands, pp. 179-251. ISBN: 978-1-4020-6662-7. DOI: 10 .1007/978-1-4020-6662-7_5. URL: http: / /www . springerlink. com/content/w3948tt7618421x7/abstract/ (visited on 03/19/2012).

Allen, Meghan et al. (2008). "Involving domain experts in assistive technology research". In: Universal Access in the Information Society 7 (3), pp. 145-154. ISSN: 1615-5289. DOI: 10 .1007/s10209-008-0112-5. URL: http: / / www . springerlink.com / content/r960k65581q1451w/abstract/ (visited on 06/01/2012).

Appleyard, Richard (2005). “Disability Informatics". In: Consumer Health Informatics. Ed. by Deborah Lewis et al. Health Informatics. Springer New York, pp. 129-142. ISBN: 978-0-387-27652-6. URL: http : / / www . springerlink . com / content / u 4 3vu 75m58695482/abstract/ (visited on 06/01/2012).

Árnason, Viljhámur, Hongwen Li, and Yali Cong (2011). "Informed Consent". In: The SAGE Handbook of Health Care Ethics. Core and Emerging Issues. Ed. by Ruth Chadwick, Henk ten Have, and Eric M. Meslin. Los Angeles, London, New Delhi, Singapore, Washington DC: SAGE Publication Inc. Chap. 10, pp. 106-116. ISBN: 978-1-4129-45349. DOI: $10.4135 / 9781446200971$. URL: http: / / knowledge. sagepub . com/ view/hdbk_healthcareethics/SAGE.xml.

Astell, Arlene et al. (2009). "Involving older people with dementia and their carers in designing computer based support systems: some methodological considerations". In: Universal Access in the Information Society 8 (1), pp. 49-58. ISSN: 1615-5289. DOI: 10.1007/s10209-008-0129-9. URL: http: / / www. springerlink.com / content/x100235u06860736/abstract/ (visited on 06/01/2012).

Batchelor, Rachel et al. (2012). “Challenges of ethical and legal responsibilities when technologies' uses and users change: social networking sites, decision-making capacity and dementia". In: Ethics and Information Technology 14 (2), pp. 99-108. ISSN: 13881957. DOI: $10.1007 /$ s10676-012-9286-x. URL: http: / /www.springerlink. com/content/850115318g6rm143/abstract/ (visited on 06/01/2012).

Beauchamp, Tom L. and James F. Childress (2009). Principles of Biomedical Ethics. 6th ed. New York, Oxford: Oxford University Press. ISBN: 978-0-19-533570-5.

Belbachir, A. N. et al. (2010). “Biologically-inspired stereo vision for elderly safety at home". In: Elektrotechnik und Informationstechnik 127 (7), pp. 216-222. ISSN: 0932-383X. DOI: 10 .1007/s502-010-0750-1. URL: http://www.springerlink.com/ content/kn7541h3h5nu82t8/abstract/ (visited on 04/05/2012).

Bermingham, Adam et al. (2013). Automatically Recommending Multimedia Content for Use in Group Reminiscence Therapy. Barcelona, Spain: 1st ACM MM Workshop on Multimedia Indexing and information Retrieval for Healthcare - MIIRH'13. 
Beyleveld, Deryck (2011). "Privacy, Confidentiality and Data Protection. Core and Emerging Issues". In: The SAGE Handbook of Health Care Ethics. Ed. by Ruth Chadwick, Henk ten Have, and Eric M. Meslin. Los Angeles, London, New Delhi, Singapore, Washington DC: SAGE Publication Inc. Chap. 9, pp. 95-105. ISBN: 978-1-4129-4534-9. DOI: 10 . 4135/9781446200971. URL: http: / / knowledge. sagepub.com / view/hdbk_healthcareethics/SAGE.xml.

Borenstein, Jason and Yvette Pearson (2010). "Robot caregivers: harbingers of expanded freedom for all?" In: Ethics and Information Technology 12 (3), pp. 277-288. ISSN: 13881957. DOI: 10.1007 /s10676-010-9236-4. URL: http: / /www. springerlink. com/content/736g221141661107/abstract/ (visited on 06/01/2012).

Broek, Ger van den, Filippo Cavallo, and Christian Wehrmann, eds. (2010). AALIANCE Ambient Assisted Living Roadmap. Vol. 6. Ambient Intelligence and Smart Environments (AISE). Amsterdam: IOS Press. ISBN: 978-1-60750-499-3.

Brown, S et al. (2004). "Care in the Community". In: BT Technology Journal 22 (3), pp. 5664. ISSN: 1358-3948. DOI: 10.1023 /B:BTTJ . 0000047120.60489 .7 a. URL: http: //www. springerlink. com/content/u77r735253658wvq/abstract/ (visited on $06 / 01 / 2012)$.

- (2006). "Care in the Community". In: Intelligent Spaces. Ed. by Alan Steventon and Steve Wright. Computer Communications and Networks. Springer London, pp. 6580. ISBN: 978-1-84628-429-8. DOI: 10 .1007/978-1-84628-429-8_5. URL: http: / / www. springerlink. com/ content/p4034u527vm56468/abstract/ (visited on $06 / 01 / 2012$ ).

Burleson, Winslow, Naomi Newman, and Ryan Brotman (2012). “Empowering Independent Living for People with Autism: Designing Supportive, Low-Cost, Interactive E-Health Environments". In: Persuasive Technology. Design for Health and Safety. Ed. by Magnus Bang and Eva L. Ragnemalm. Red. by Gerhard ikum. Vol. 7284. Berlin, Heidelberg: Springer Berlin / Heidelberg, pp. 13-30. ISBN: 978-3-642-310362, 978-3-642-31037-9. DOI: 10 . $1007 / 978-3-642-31037-9$ 2. URL: http : / / www . springerlink. com/index/10 . 1007/978-3-642-31037-9_2 (visited on 04/10/2013).

Cahill, Suzanne et al. (2007). "Technology in dementia care". In: Technology and Disability 19.2, pp. 55-60. URL: http: / / hdl . handle. net/2262/49835.

Camarinha-Matos, Luis and Hamideh Afsarmanesh (2011). "Collaborative Ecosystems in Ageing Support". In: Adaptation and Value Creating Collaborative Networks. Ed. by Luis M. Camarinha-Matos, Alexandra Pereira-Klen, and Hamideh Afsarmanesh. Vol. 362. IFIP Advances in Information and Communication Technology. Springer Boston, pp. 177-188. ISBN: 978-3-642-23329-6. DOI: 10 . 1007 / $978-3-$ 642-23330-2_20. URL: http : / / www . springerlink. com / content / 7v6×3w0h34403q26/abstract/ (visited on 04/05/2012).

Cavoukian, Ann et al. (2010). "Remote home health care technologies: how to ensure privacy? Build it in: Privacy by Design". In: Identity in the Information Society 3 (2), pp. 363-378. ISSN: 1876-0678. DOI: 10.1007 / s12394-010-0054-y. URL: http: / / www.springerlink.com/content/u0678r87r4802648/abstract/ (visited on $06 / 01 / 2012)$. 
Chadwick, Ruth, Henk ten Have, and Eric M. Meslin, eds. (2011). The SAGE Handbook of Health Care Ethics. Core and Emerging Issues. Los Angeles, London, New Delhi, Singapore, Washington DC: SAGE Publication Inc. ISBN: 978-1-4129-4534-9. DOI: 10 . 4135/9781446200971. URL: http: / / knowledge. sagepub . com/view / hdbk_healthcareethics/SAGE.xml.

Chan, Marie, Eric Campo, et al. (2009). "Smart homes - Current features and future perspectives". In: Maturitas 64 (2), pp. 90-97. ISSN: 03785122. DOI: $10.1016 / \mathrm{j}$. maturitas .2009.07 .014. URL: http: / / linkinghub. elsevier.com / retrieve/pii/S0378512209002606 (visited on 04/05/2012).

Chan, Marie, Daniel Estève, et al. (2008). "A review of smart homes-Present state and future challenges". In: Computer Methods and Programs in Biomedicine 91 (1), pp. 5581. ISSN: 01692607. DOI: $10.1016 / j$. cmpb . 2008 . 02 .001. URL: http : / / linkinghub.elsevier.com/retrieve/pii/s0169260708000436 (visited on $04 / 05 / 2012)$.

Coeckelbergh, Mark (2010). "Health Care, Capabilities, and AI Assistive Technologies". In: Ethical Theory and Moral Practice 13 (2), pp. 181-190. ISSN: 1386-2820. DOI: 10 .1007/s10677-009-9186-2. URL: http: / / www . springerlink.com / content/y6j9244p317q318g/abstract/ (visited on 06/01/2012).

- (2012). "'How I Learned to Love the Robot": Capabilities, Information Technologies, and Elderly Care". In: The Capability Approach, Technology and Design. Ed. by Ilse Oosterlaken et al. Vol. 5. Philosophy of Engineering and Technology. Springer Netherlands, pp. 77-86. ISBN: 978-94-007-3879-9. URL: http : / / www . springerlink . com/content/n252613515862624/abstract/ (visited on 06/01/2012).

Conley, Edward et al. (2008). "Simultaneous trend analysis for evaluating outcomes in patient-centred health monitoring services". In: Health Care Management Science 11 (2), pp. 152-166. ISSN: 1386-9620. DOI: 10.1007 /s10729-008-9061-z. URL: http: / / www.springerlink.com/content/c41522704g744755/abstract/ (visited on $06 / 01 / 2012)$.

Cook, Diane J., Juan C. Augusto, and Vikramaditya R. Jakkula (2009). “Ambient intelligence: Technologies, applications, and opportunities". In: Pervasive and Mobile Computing 5 (4), pp. 277-298. ISSN: 15741192. DOI: $10.1016 / j$. pmcj . 2009. 04 . 001 . URL: http : / / linkinghub . elsevier . com / retrieve / pii / S157411920900025X (visited on 04/05/2012).

Daniel, Kathryn M., Carolyn L. Cason, and Sherry Ferrell (2009). “Emerging Technologies to Enhance the Safety of Older People in Their Homes". In: Geriatric Nursing 30 (6), pp. 384-389. ISSN: 01974572. DOI: 10 . $1016 / j$.gerinurse. 2009.08.010. URL: http:// linkinghub.elsevier.com/retrieve/pii/ S 0197457209003139 (visited on 04/05/2012).

Darwish, Ashraf and Aboul Ella Hassanien (2011). "Wearable and Implantable Wireless Sensor Network Solutions for Healthcare Monitoring". In: Sensors 11 (6), pp. 55615595. ISSN: 1424-8220. DOI: 10 . 3390 / s110605561. URL: http : / / www . mdpi . $\mathrm{com} / 1424-8220 / 11 / 6 / 5561 /$ (visited on 03/19/2012).

Darzentas, Jenny and Klaus Miesenberger (2005). “Design for All in Information Technology: A Universal Concern". In: Database and Expert Systems Applications. Ed. by Kim Andersen, John Debenham, and Roland Wagner. Vol. 3588. Lecture Notes in 
Computer Science. Springer Berlin / Heidelberg, pp. 406-420. ISBN: 978-3-540-285663. URL: http: / / www . springerlink. com / content / bw7p6x2leuq6nama / abstract / (visited on 06/01/2012).

Decker, Michael (2012). "Service robots in the mirror of reflective research". In: Poiesis $\mathcal{E}$ Praxis 9 (3-4), pp. 181-200. ISSN: 1615-6609, 1615-6617. DOI: 10.1007 / s $10202-012-$ 0111-8. URL: http: / / link. springer.com/10.1007/s10202-012-0111-8 (visited on 04/10/2013).

Decker, Michael et al. (2011). "Service robotics: do you know your new companion? Framing an interdisciplinary technology assessment". In: Poiesis $\mathcal{E}$ Praxis: International Journal of Technology Assessment and Ethics of Science 8 (1), pp. 25-44. ISSN: 16156609. DOI: $10.1007 /$ s10202-011-0098-6. URL: http: / /wWw. springerlink. com/content/e00675737v132x70/abstract/ (visited on 04/05/2012).

Dekkers, Wim (2009). "On the notion of home and the goals of palliative care". In: Theoretical Medicine and Bioethics 30 (5), pp. 335-349. ISSN: 1386-7415. DOI: 10.1007 / s11017-009-9121-5. URL: http: / / www . springerlink . com/ content / j73w350n75176851/abstract/ (visited on 06/01/2012).

Dishman, Eric and Maria C. Carrillo (2007). "Perspective on everyday technologies for Alzheimer's care: Research findings, directions, and challenges". In: Alzheimer's and Dementia 3 (3), pp. 227-234. ISSN: 15525260. DOI: $10.1016 /$ j. jalz . 2007. 04 . 387. URL: http : / / linkinghub . elsevier . com / retrieve / pii / S1552526007004827 (visited on 04/05/2012).

Doorn, Neelke (2010). "A procedural approach to distributing responsibilities in R\&D networks". In: Poiesis E Praxis: International Journal of Technology Assessment and Ethics of Science 7 (3), pp. 169-188. ISSN: 1615-6609, 1615-6617. DOI: 10.1007 / s10202010-0086-2. URL: http: / / www . springerlink. com/index/10 . 1007 / s10202-010-0086-2 (visited on 03/19/2012).

Duquenoy, Penny (2004). “Intelligent Ethics”. In: Building the Information Society. Ed. by Renè Jacquart. In collab. with Renè Jacquart. Vol. 156. IFIP International Federation for Information Processing. Springer Boston, pp. 597-602. ISBN: 978-1-4020-8156-9. DOI: 10 .1007/978-1-4020-8157-6_56. URL: http: //www. springerlink. com/content/387153165380j771/abstract/ (visited on 03/19/2012).

Duquenoy, Penny and Diane Whitehouse (2006). "A 21st century ethical debate: Pursuing perspectives on ambient intelligence". English. In: The Information Society: Emerging Landscapes. Ed. by Chris Zielinski, Penny Duquenoy, and Kai Kimppa. Vol. 195. IFIP International Federation for Information Processing. WOS:000235187200018. New York: Springer, pp. 293-314. ISBN: 978-0-387-30527-1. DOI: 10 . $1007 / 0-387-$ 31168-8_18. URL: http: / / link. springer.com/ chapter/10 . 1007/0387-31168-8_18.

Emanuel, Ezekiel J., David Wendler, and Christine Grady (2000). “What Makes Clinical Research Ethical?" In: The Journal of the American Medical Association 283.20, pp. 27012711. DOI: $10.1001 /$ jama .283 .20 .2701. eprint: http: / / jama . ama-assn . org/ content/283/20/2701. full.pdf+html. URL: http: / / jama . amaassn.org/content/283/20/2701.abstract.

Emanuel, Ezekiel J., David Wendler, Jack Killen, et al. (2004). “What Makes Clinical Research in Developing Countries Ethical? The Benchmarks of Ethical Re- 
search". In: The Journal of Infectious Diseases 189, pp. 930-7. URL: http : / / jid . oxfordjournals.org/content/189/5/930.full.pdf.

Eurostat (2011). Population projections. European Commission. URL: http : / / epp . eurostat . ec . europa . eu / statistics_explained / index . php / Population_projections.

Fairclough, Stephen H. (2009). "Fundamentals of physiological computing". In: Interacting with Computers 21 (1-2), pp. 133-145. ISSN: 09535438. DOI: 10.1016 / j. intcom. 2008.10.011. URL: http:// linkinghub. elsevier.com/retrieve/pii/ S0953543808000738 (visited on 03/19/2012).

Foddy, Bennett (2012). "The Right and Wrong of Growing Old: Assessing the Argument from Evolution". In: Philosophy E Technology, pp. 1-14. ISSN: 2210-5433. DOI: 10 .1007/s13347-012-0066-7. URL: http: / / www . springerlink.com / content/f05420g5320v6p74/abstract / (visited on 06/01/2012).

Francis, Peter, Sandrine Balbo, and Lucy Firth (2009). "Towards co-design with users who have autism spectrum disorders". In: Universal Access in the Information Society 8 (3), pp. 123-135. ISSN: 1615-5289, 1615-5297. DOI: 10 . 1007 / s10209-008-0143-y. URL: http: / / www . springerlink . com/index/10 . 1007/s10209-008$0143-y$ (visited on 03/19/2012).

Friedewald, Michael and Oliver Raabe (2011). "Ubiquitous computing: An overview of technology impacts". In: Telematics and Informatics 28 (2), pp. 55-65. ISSN: 07365853. DOI: $10.1016 / j$.tele.2010.09.001. URL: http: / / inkinghub.elsevier. com/retrieve/pii/s 0736585310000547 (visited on 04/05/2012).

Gaul, Sylvia and Martina Ziefle (2009). "Smart Home Technologies: Insights into Generation-Specific Acceptance Motives". In: HCI and Usability for e-Inclusion. Ed. by Andreas Holzinger and Klaus Miesenberger. Vol. 5889. Berlin, Heidelberg: Springer Berlin Heidelberg, pp. 312-332. ISBN: 978-3-642-10307-0, 978-3-642-10308-7. DOI: 10.1007/978-3-642-10308-7_22. URL: http://www.springerlink.com/ index/10.1007/978-3-642-10308-7_22 (visited on 04/11/2013).

Grönvall, Erik and Morten Kyng (2012). “On participatory design of home-based healthcare". In: Cognition, Technology \& Work. ISSN: 1435-5558, 1435-5566. DOI: 10 . 1007/s10111-012-0226-7. URL: http: / / link. springer.com/10.1007/ s10111-012-0226-7 (visited on 04/10/2013).

Harrefors, Christina et al. (2012). "Professional Caregivers' Perception on how Persons with Mild Dementia Might Experience the Usage of a Digital Photo Diary". In: The Open Nursing Journal 6, pp. 20-29. URL: http: / / www.ncbi.nlm.nih.gov/pmc/ articles/PMC3322432/.

Hersh, Marion et al. (2003). "The Final Product: Issues in the Design and Distribution of Assistive Technology Devices". In: Hersh, Marion and Michael Johnson. Assistive Technology for the Hearing-impaired, Deaf and Deafblind. Ed. by Marion Hersh and Michael Johnson. Springer London. Chap. 9, pp. 297-305. ISBN: 978-1-85233-8558. URL: http : / / www . springerlink. com / content/u252252037780k71/ abstract / (visited on 06/01/2012).

Hofmann, Bjørn (2012). "Ethical Challenges with Welfare Technology: A Review of the Literature". In: Science and Engineering Ethics 19.2, pp. 389-406. ISSN: 1353-3452, 1471- 
5546. DOI: $10.1007 /$ s11948-011-9348-1. URL: http: / /www. springerlink . com/index/10.1007/s11948-011-9348-1 (visited on 03/19/2012).

Holzinger, Andreas, Klaus Schaupp, and Walter Eder-Halbedl (2008). “An Investigation on Acceptance of Ubiquitous Devices for the Elderly in a Geriatric Hospital Environment: Using the Example of Person Tracking". In: Computers Helping People with Special Needs. Ed. by Klaus Miesenberger et al. Vol. 5105. Lecture Notes in Computer Science. Springer Berlin / Heidelberg, pp. 22-29. ISBN: 978-3-540-70539-0. URL: http: //www. springerlink. com/ content/3utr4w5t310t3524/abstract/ (visited on 06/01/2012).

Kang, Hyun Gu et al. (2010). "In Situ Monitoring of Health in Older Adults: Technologies and Issues". English. In: Journal of the American Geriatrics Society 58 (8). WOS:000280643700023, pp. 1579-1586. ISSN: 0002-8614. DOI: 10.1111 / j . 1532 $5415.2010 .02959 . x$.

Kaye, Jeffrey (2010). “Technology and Dementia: The Way Ahead". In: Supporting People with Dementia Using Pervasive Health Technologies. Ed. by Maurice D. Mulvenna and Chris D. Nugent. Advanced Information and Knowledge Processing. Springer London, pp. 221-234. ISBN: 978-1-84882-551-2. DOI: 10 . 1007/978-1-84882-551-2_ 15. URL: http: / / www . springerlink. com/ content/u835138116657541/ abstract / (visited on 06/01/2012).

Kleinberger, Thomas et al. (2007). “Ambient Intelligence in Assisted Living: Enable Elderly People to Handle Future Interfaces". In: Universal Access in Human-Computer Interaction. Ambient Interaction. Ed. by Constantine Stephanidis. Vol. 4555. Berlin, Heidelberg: Springer Berlin Heidelberg, pp. 103-112. ISBN: 978-3-540-73280-8. URL: http: / / www . springerlink. com/index/10 .1007/978-3-540-732815_11 (visited on 04/11/2013).

Kosta, Eleni, Olli Pitkänen, et al. (2010). “Mobile-Centric Ambient Intelligence in Healthand Homecare-Anticipating Ethical and Legal Challenges". In: Science and Engineering Ethics 16 (2), pp. 303-323. ISSN: 1353-3452, 1471-5546. DOI: 10.1007 / s11948$009-9150$ - 5. URL: http: / / www . springerlink. com/index/10 . 1007 / s11948-009-9150-5 (visited on 03/19/2012).

Kosta, Eleni, O. Pitkanen, et al. (2008). "Ethical-Legal Challenges in User-Centric AmI Services". English. In: 3rd International Conference On Internet And Web Applications And Services (ICIW 2008). Ed. by A Mellouk et al. WOS:000290504500004. New York: IEEE, pp. 19-24. ISBN: 978-1-4244-4238-6. DOI: 10.1109 / ICIW. 2008 . 81.

Kumar, Pardeep and Hoon-Jae Lee (2011). “Security Issues in Healthcare Applications Using Wireless Medical Sensor Networks: A Survey". In: Sensors 12 (1), pp. 55-91. ISSN: 1424-8220. DOI: 10 . $3390 /$ s 120100055 . URL: http : / / www . mdpi . com / $1424-8220 / 12 / 1 / 55 /$ (visited on 03/19/2012).

Landau, Ruth and Shirli Werner (2012). "Ethical aspects of using GPS for tracking people with dementia: recommendations for practice". English. In: International Psychogeriatrics 24 (3). WOS:000299878600003, pp. 358-366. ISSN: 1041-6102. DOI: 10 .1017/S1041610211001888. URL: http: / / journals . cambridge.org / action/displayAbstract? fromPage=online\&aid=8478561.

Lauriks, Steve et al. (2010). "Review of ICT-Based Services for Identified Unmet Needs in People with Dementia". In: Supporting People with Dementia Using Pervasive Health 
Technologies. Ed. by Maurice D. Mulvenna and Chris D. Nugent. Advanced Information and Knowledge Processing. Springer London, pp. 37-61. ISBN: 978-1-84882-5512. URL: http: / / www . springerlink . com / content/rr54254556317513 / abstract/ (visited on 06/01/2012).

Lauriks, S. et al. (2007). "Review of ICT-based services for identified unmet needs in people with dementia". In: Ageing Research Reviews 6 (3), pp. 223-246. ISSN: 15681637. DOI: $10.1016 / j$.arr.2007.07.002. URL: http: / / linkinghub.elsevier. com/retrieve/pii/S1568163707000372 (visited on 04/05/2012).

Lorenzen-Huber, Lesa et al. (2011). "Privacy, Technology, and Aging: A Proposed Framework”. In: Ageing International 36 (2), pp. 232-252. ISSN: 0163-5158. DOI: 10.1007 / s12126-010-9083-y. URL: http: / / www . springerlink . com/ content / 44 r0714314r03986/abstract/ (visited on 06/01/2012).

Lynch, Scott M., J. Scott Brown, and Miles G. Taylor (2009). “Demography of Disability". In: International Handbook of Population Aging. Ed. by Peter Uhlenberg. Vol. 1.5. International Handbooks of Population. Springer Netherlands, pp. 567-582. ISBN: 978-1-4020-8356-3. DOI: 10 .1007/978-1-4020-8356-3_25. URL: http: / /www .

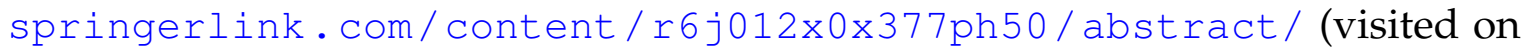
06/01/2012).

Maguire, Martin et al. (2011). "A Study of User Needs for the 'Techno Kitchen'”. In: HCI International 2011 - Posters' Extended Abstracts. Ed. by Constantine Stephanidis. In collab. with Constantine Stephanidis. Vol. 174. Communications in Computer and Information Science. Springer Berlin Heidelberg, pp. 66-71. ISBN: 978-3-642-22095-1. DOI: 10 .1007/978-3-642-22095-1_14. URL: http: //www . springerlink. com/content/n060j1776861wg08/abstract/ (visited on 03/19/2012).

Maier, Edith and Guido Kempter (2009). "AAL in the Wild - Lessons Learned". In: Universal Access in Human-Computer Interaction. Intelligent and Ubiquitous Interaction Environments. Ed. by Constantine Stephanidis. In collab. with Constantine Stephanidis. Vol. 5615. Lecture Notes in Computer Science. Springer Berlin / Heidelberg, pp. 218-227. ISBN: 978-3-642-02709-3. DOI: 10 . $1007 / 978-3-642-02710-9$ 25. URL: http : / / www . springerlink . com / content / m876mx227lk472u1 / abstract / (visited on 04/05/2012).

Mandell, Alan M. and Robert C. Green (2011). "Alzheimer's Disease". In: The Handbook of Alzheimer's Disease and Other Dementias. Ed. by Andrew E. Budson and Neil W. Kowall. .1. Wiley-Blackwell Handbooks of Behavioral Neuroscience. Oxford: Blackwell Publishing, pp. 3-92. ISBN: 978-1-4051-6828-1.

Martin, Suzanne, Johan E. Bengtsson, and Rose-Marie Dröes (2010). "Assistive Technologies and Issues Relating to Privacy, Ethics and Security". In: Supporting People with Dementia Using Pervasive Health Technologies. Ed. by Maurice D. Mulvenna and Chris D. Nugent. Advanced Information and Knowledge Processing. Springer London, pp. 63-76. ISBN: 978-1-84882-551-2. URL: http: / / www . springerlink . com/ content / j576272k13461370/abstract / (visited on 06/01/2012).

McHugh, Joanna et al. (2012).Dem@Care: a proposed system for the home-based ambient monitoring and enablement of older adults with dementia. Poster. Cork, Ireland: Irish Gerontological Society Conference. URL: http: / / doras.dcu.ie/17527/. 
McLean, Athena (2011). "Ethical frontiers of ICT and older users: cultural, pragmatic and ethical issues". In: Ethics and Information Technology 13 (4), pp. 313-326. ISSN: 13881957. DOI: $10.1007 /$ s10676-011-9276-4. URL: http: / /www. springerlink. com/content/008203×445420048/abstract/ (visited on 06/01/2012).

Mepham, Ben (2008). Bioethics - An introduction for the biosciences. 2nd ed. USA: Oxford University Press. 440 pp. ISBN: 978-0-19-921430-3. URL: http: / / ukcatalogue. oup.com/product/9780199214303.do.

Merilahti, Juho, Juha Pärkkä, and Ilkka Korhonen (2012). “Estimating Older People's Physical Functioning with Automated Health Monitoring Technologies at Home: Feature Correlations and Multivariate Analysis". In: Grid and Pervasive Computing Workshops. Ed. by Mika Rautiainen et al. Vol. 7096. Lecture Notes in Computer Science. Springer Berlin / Heidelberg, pp. 94-104. ISBN: 978-3-642-27915-7. URL: http: //www. springerlink. com/content/k3646361885nt7r1/abstract/ (visited on 06/01/2012).

Mordini, Emilio et al. (2009). "Senior citizens and the ethics of e-inclusion". In: Ethics and Information Technology 11 (3), pp. 203-220. ISSN: 1388-1957. DOI: 10 . 1007 / s10676-009-9189-7. URL: http: / / www . springerlink . com / content / 55w76284760740w4/abstract/ (visited on 04/05/2012).

Nations, United (2006). World Population Prospects: The 2006 Revision. Population Ageing. Report. United Nations. URL: http: / / www . un . org / esa / population / publications/wpp2006/wpp2006_ageing •pdf.

Newell, A. et al. (2011). “User-Sensitive Inclusive Design". In: Universal Access in the Information Society 10 (3), pp. 235-243. ISSN: 1615-5289. DOI: 10 . 1007 / s10209-010-0203-y. URL: http: / / www . springerlink. com/ content / lq36q58020437864/abstract/ (visited on 06/01/2012).

Niemelä, Marketta et al. (2007). "Supporting Independent Living of the Elderly with Mobile-Centric Ambient Intelligence: User Evaluation of Three Scenarios". In: Ambient Intelligence. Ed. by Bernt Schiele et al. Vol. 4794. Lecture Notes in Computer Science. Springer Berlin / Heidelberg, pp. 91-107. ISBN: 978-3-540-76651-3. DOI: 10.1007/978-3-540-76652-0_6. URL: http: //www.springerlink.com/ content/v03558301124634l/abstract/ (visited on 06/01/2012).

Noury, Norbert et al. (2011). "Smart Sweet Home... A Pervasive Environment for Sensing our Daily Activity?" In: Activity Recognition in Pervasive Intelligent Environments. Ed. by Liming Chen et al. Vol. 4. Atlantis Ambient and Pervasive Intelligence. Atlantis Press, pp. 187-208. ISBN: 978-94-91216-05-3. URL: http : / / www . springerlink. com/content/m53742450r245138/abstract/ (visited on 06/01/2012).

Oberzaucher, Johannes et al. (2009). “A Videophone Prototype System Evaluated by Elderly Users in the Living Lab Schwechat". In: HCI and Usability for e-Inclusion. Ed. by Andreas Holzinger and Klaus Miesenberger. In collab. with Andreas Holzinger and Klaus Miesenberger. Vol. 5889. Lecture Notes in Computer Science. Springer Berlin / Heidelberg, pp. 345-352. ISBN: 978-3-642-10307-0. DOI: 10 . 1007 / $978-$ 3-642-10308-7_24. URL: http: //www. springerlink. com/content / $5167613026 \mathrm{~h} 717 \mathrm{mr} / \mathrm{abstract} /$ (visited on 04/05/2012). 
O’Neill, Sonja A., Sarah Mason, et al. (2011). "Video Reminders as Cognitive Prosthetics for People with Dementia". In: Ageing International 36 (2), pp. 267-282. ISSN: 01635158. DOI: $10.1007 /$ s12126-010-9089-5. URL: http: / /www. springerlink. com/content/e63623936g2gt257/abstract/ (visited on 06/01/2012).

O’Neill, Sonja A., Guido Parente, et al. (2011). “Assessing Task Compliance Following Mobile Phone-Based Video Reminders". In: Engineering in Medicine and Biology Society, EMBC, 2011 Annual International Conference of the IEEE, pp. 5295-8. DOI: 10.1109/IEMBS . 2011.6091310. URL: http: / / ieeexplore. ieee.org / xpl/articleDetails.jsp?arnumber $=6091310$.

Oost, Ellen and Darren Reed (2011). “Towards a Sociological Understanding of Robots as Companions". In: Human-Robot Personal Relationships. Ed. by Maarten H. Lamers and Fons J. Verbeek. In collab. with Maarten H. Lamers and Fons J. Verbeek. Vol. 59. Lecture Notes of the Institute for Computer Sciences, Social Informatics and Telecommunications Engineering. Springer Berlin Heidelberg, pp. 11-18. ISBN: 978-3-642-193859. URL: http: / / www . springerlink. com / content / wx75 j3gg01342q4v / abstract / (visited on 04/05/2012).

Oppenauer, Claudia et al. (2007). "Technology in Old Age from a Psychological Point of View". In: HCI and Usability for Medicine and Health Care. Ed. by Andreas Holzinger. Vol. 4799. Berlin, Heidelberg: Springer Berlin / Heidelberg, pp. 133-142. ISBN: 9783-540-76804-3. DOI: 10 . 1007/978-3-540-76805-0_11. URL: http: / / www . springerlink.com/index/10.1007/978-3-540-76805-0_11 (visited on 04/11/2013).

Palm, Elin (2012). "A Declaration of Healthy Dependence: The Case of Home Care". In: Health Care Analysis. ISSN: 1065-3058, 1573-3394. DOI: 10.1007 / s10728-0120228-x. URL: http: // link. springer.com/10.1007/s10728-012-0228-x (visited on $04 / 10 / 2013$ ).

Panek, P. and W. L. Zagler (2008). "A Living Lab for Ambient Assisted Living in the Municipality of Schwechat". In: Computers Helping People with Special Needs. Ed. by Klaus Miesenberger et al. In collab. with Klaus Miesenberger et al. Vol. 5105. Lecture Notes in Computer Science. Springer Berlin / Heidelberg, pp. 1008-1015. ISBN: 9783-540-70539-0. DOI: 10 .1007/978-3-540-70540-6_151. URL: http: / / www . springerlink. com/content / xq654k6883u46018/abstract/ (visited on 04/05/2012).

Piasek, Paulina, Kate Irving, and Alan F. Smeaton (2013). "Case study in SenseCam use as an intervention technology for early-stage dementia". In: International Journal of Computers in Helathcare 1.4, pp. 304-319. ISSN: 1755-3202. URL: http : / doras . deu. ie/17745/.

Picking, Rich et al. (2012). "The Easyline+ project: evaluation of a user interface developed to enhance independent living of elderly and disabled people". In: Universal Access in the Information Society 11 (2), pp. 99-112. ISSN: 1615-5289, 1615-5297. DOI: 10 . 1007 / s10209-011-0246-8. URL: http: / / www . springerlink . com / index/10.1007/s10209-011-0246-8 (visited on 03/19/2012).

Plaza, Inmaculada et al. (2011). "Mobile applications in an aging society: Status and trends". In: Journal of Systems and Software 84 (11), pp. 1977-1988. ISSN: 01641212. 
DOI: $10.1016 / j . j s s .2011 .05 .035$. URL: http:// linkinghub. elsevier. com/retrieve/pii/s $016412121100135 x$ (visited on 04/05/2012).

Portet, François et al. (2011). "Design and evaluation of a smart home voice interface for the elderly: acceptability and objection aspects". In: Personal and Ubiquitous Computing, pp. 127-144. ISSN: 1617-4909, 1617-4917. DOI: 10.1007 / s $00779-011-$ 0470 - 5. URL: http: / / www. springerlink. com/index/10.1007/s00779011-0470-5 (visited on 03/19/2012).

Pulli, Petri et al. (2012). "User interaction in smart ambient environment targeted for senior citizen". In: Medical and Biological Engineering and Computing, pp. 1-8. ISSN: 0140-0118. DOI: 10 . 1007/s11517-012-0906-8. URL: http : / / www . springerlink. com/content/p5353062t37t0t73/abstract/ (visited on 06/01/2012).

Rapoport, Michele (2012). "Being a body or having one: automated domestic technologies and corporeality". In: AI \& SOCIETY 28 (2), pp. 209-218. ISSN: 0951-5666, 14355655. DOI: 10.1007 /s $00146-012-0406-2$. URL: http: / / www . springerlink. com/index/10.1007/s00146-012-0406-2 (visited on 03/19/2012).

Remmers, Hartmut (2010). “Environments for ageing, assistive technology and selfdetermination: ethical perspectives". English. In: Informatics for Health $\mathcal{E}$ Social Care 35 (3-4). WOS:000285003100009, pp. 200-210. ISSN: 1753-8157. DOI: 10 . 3109 / 17538157 . 2010 . 528649. URL: http: / / informahealthcare . com / doi / abs/10.3109/17538157.2010.528649.

Robinson, Louise et al. (2009). “Keeping In Touch Everyday (KITE) project: developing assistive technologies with people with dementia and their carers to promote independence". English. In: International Psychogeriatrics 21 (3). WOS:000266567800011, pp. 494-502. ISSN: 1041-6102. DOI: 10.1017 /S1041610209008448.

Robinson, L. et al. (2007). "Balancing rights and risks: Conflicting perspectives in the management of wandering in dementia". English. In: Health Risk $\mathcal{E}$ Society 9 (4). WOS:000250225000004, pp. 389-406. ISSN: 1369-8575. DOI: 10 . 1080 / 13698570701612774. URL: http: / / www . tandfonline.com/doi/abs / 10 . $1080 / 13698570701612774$.

Román, Isabel, Jorge Calvillo, and Laura M. Roa (2009). “Personalizing Care: Integration of Hospital and Homecare". In: Handbook of Digital Homecare. Ed. by Kanagasingam Yogesan et al. Series in Biomedical Engineering. Springer Berlin Heidelberg, pp. 3352. ISBN: 978-3-642-01387-4. DOI: 10 .1007/978-3-642-01387-4_3. URL: http: //www. springerlink. com/ content/w2k5767t2281 j5q5/abstract/ (visited on 06/01/2012).

Romdhane, R. et al. (2012). "Automatic video monitoring system for assessment of Alzheimer's Disease symptoms". In: The Journal of Nutrition, Health $\mathcal{E}$ Aging 16 (3), pp. 213-218. ISSN: 1279-7707. DOI: 10.1007 /s12603-012-0039-7. URL: http: / / wWw. springerlink.com/content/y2hq46ht57730311/abstract/ (visited on $06 / 01 / 2012)$.

Salces, Fausto et al. (2006). "Ambient Interfaces for Elderly People at Home". In: Ambient Intelligence in Everyday Life. Ed. by Yang Cai and Julio Abascal. Vol. 3864. Lecture Notes in Computer Science. Springer Berlin / Heidelberg, pp. 256-284. ISBN: 978-3- 
540-37785-6. DOI: 10.1007 /11825890_13. URL: http: / / www . springerlink . com/content/u 5m×624xv252g233/abstract/ (visited on 06/01/2012).

Satava, Richard M. (2003). "Biomedical, Ethical, and Moral Issues Being Forced by Advanced Medical Technologies". In: Proceedings of the American Philosophical Society 147.3, pp. 246-258. URL: http: / / www. jstor.org/stable/1558213.

Scanaill, Cliodhna et al. (2006). "A Review of Approaches to Mobility Telemonitoring of the Elderly in Their Living Environment". In: Annals of Biomedical Engineering 34 (4), pp. 547-563. ISSN: 0090-6964. DOI: 10.1007 / s $10439-005-9068-2$. URL: http: / / www.springerlink.com/content/8lv188303p742g86/abstract/ (visited on $06 / 01 / 2012$ ).

Sharkey, Amanda and Noel Sharkey (2012). "Granny and the robots: ethical issues in robot care for the elderly". In: Ethics and Information Technology 14 (1), pp. 2740. ISSN: 1388-1957. DOI: 10 . 1007 / s10676-010-9234-6. URL: http: / / www . springerlink. com/content/nn452hh1p3t37732/abstract/ (visited on 06/01/2012).

Sixsmith, Andrew and Judith Sixsmith (2008). "Ageing in Place in the United Kingdom". In: Ageing International 32 (3), pp. 219-235. ISSN: 0163-5158. DOI: 10.1007 / s12126-008-9019-y. URL: http : / / www . springerlink . com/ content / c34235804mg63p8w/abstract/ (visited on 06/01/2012).

Sorell, Tom and Heather Draper (2012). "Telecare, Surveillance, and the Welfare State". In: American Journal of Bioethics 12 (9). WOS:000307451500014, pp. 36-44. DOI: 10 . 1080/15265161.2012.699137. URL: http: / / www.tandfonline.com/doi/ abs/10.1080/15265161.2012.699137.

Sparrow, Robert and Linda Sparrow (2006). "In the hands of machines? The future of aged care". In: Minds and Machines 16 (2), pp. 141-161. ISSN: 0924-6495. DOI: 10.1007/s11023-006-9030-6. URL: http: / / www . springerlink.com / content/f2t210488724v482/abstract/ (visited on 06/01/2012).

Spiekermann, Sarah and Frank Pallas (2006). “Technology paternalism - wider implications of ubiquitous computing". In: Poiesis $\mathcal{E}$ Praxis: International Journal of Technology Assessment and Ethics of Science 4 (1), pp. 6-18. ISSN: 1615-6609. DOI: 10.1007/s10202-005-0010-3. URL: http: / / www. springerlink.com/ content/b2812617ug4718pv/abstract/ (visited on 03/19/2012).

Sponselee, Anne-mie et al. (2008). “Smart Home Technology for the Elderly: Perceptions of Multidisciplinary Stakeholders". In: Constructing Ambient Intelligence. Ed. by Max Mühlhäuser, Alois Ferscha, and Erwin Aitenbichler. In collab. with Max Mühlhäuser, Alois Ferscha, and Erwin Aitenbichler. Vol. 11. Communications in Computer and Information Science. Springer Berlin Heidelberg, pp. 314-326. ISBN: 978-3-540-85379-4. DOI: $10.1007 / 978-3-540-85379-4$ 37. URL: http: / / www.springerlink . com/content/r58157k2274g014n/abstract/ (visited on 03/19/2012).

Stapleton, Larry (2008). "Ethical decision making in technology development: a case study of participation in a large-scale information systems development project". In: AI E Society 22 (3), pp. 405-429. ISSN: 0951-5666. DOI: 10.1007 / s00146-007-0150-1. URL: http: / / www . springerlink . com/ content / q6621726×80244m2/abstract/ (visited on 06/01/2012). 
Statistics Bureau, Japan (2011). Statistical Handbook of Japan 2011. Handbook. Statistics Bureau and the Director-General for Policy Planning of Japan. Chap. 2. URL: http: //www.stat.go.jp/english/data/handbook/index.htm.

Stip, E. and V. Rialle (2005). "Environmental cognitive remediation in schizophrenia: Ethical implications of "smart home" technology". English. In: Canadian Journal of Psychiatry-Revue Canadienne De Psychiatrie 50 (5). WOS:000234708500009, pp. 281-291. ISSN: 0706-7437. URL: http: / /www.ncbi.nlm.nih.gov/pubmed/15968845.

Toboso, Mario (2011). "Rethinking disability in Amartya Sen's approach: ICT and equality of opportunity". In: Ethics and Information Technology 13 (2), pp. 107-118. ISSN: 1388-1957. DOI: 10 . 1007 / s10676-010-9254-2. URL: http : / / www . springerlink. com/content/n252382413544012/abstract/ (visited on 06/01/2012).

Vallor, Shannon (2011). "Carebots and Caregivers: Sustaining the Ethical Ideal of Care in the Twenty-First Century". In: Philosophy \& Technology 24 (3), pp. 251-268. ISSN: 22105433. DOI: $10.1007 /$ s13347-011-0015-x. URL: http: / / www. springerlink. com/content/p1v784663073q357/abstract/ (visited on 06/01/2012).

Van Hoof, J. et al. (2011). "Ageing-in-place with the use of ambient intelligence technology: Perspectives of older users". In: International Journal of Medical Informatics 80 (5), pp. 310-331. ISSN: 13865056. DOI: 10 . $1016 /$ j . ijmedinf . 2011. 02 . 010. URL: http : / / linkinghub . elsevier . com / retrieve / pii / S1386505611000566 (visited on 03/19/2012).

Van Wynsberghe, Aimee (2012). “Designing Robots for Care: Care Centered ValueSensitive Design". In: Science and Engineering Ethics 19 (2), pp. 407-433. ISSN: 13533452. DOI: $10.1007 /$ s11948-011-9343-6. URL: http: / /www.springerlink. com/content/j6521426463u1164/abstract/ (visited on 06/01/2012).

Viswanathan, Hariharasudhan, Baozhi Chen, and Dario Pompili (2012). "Research Challenges in Computation, Communication, and Context Awareness for Ubiquitous Healthcare". In: Communications Magazine, IEEE 50 (5), pp. 92-99. DOI: 10 . 1109 / MCOM . 2012 .6194388. URL: http: / / ieeexplore. ieee.org/xpl / articleDetails.jsp?arnumber $=6194388$.

Wallace, Jonathan et al. (2010). "ICT Interface Design for Ageing People and People with Dementia". In: Supporting People with Dementia Using Pervasive Health Technologies. Ed. by Maurice D. Mulvenna and Chris D. Nugent. With a forew. by June Andrews. Advanced Information and Knowledge Processing. London: Springer London, pp. 165188. ISBN: 978-1-84882-551-2. DOI: 10 . $1007 / 978-1-84882-551-2$. URL: http: //www. springerlink. com/content/w0717j522ux47018/abstract/ (visited on 06/01/2012).

Walsh, Kieran and Aoife Callan (2011). "Perceptions, Preferences, and Acceptance of Information and Communication Technologies in Older-Adult Community Care Settings in Ireland: A Case-Study and Ranked-Care Program Analysis". In: Ageing International 36 (1), pp. 102-122. ISSN: 0163-5158. DOI: 10.1007 / s12126-010-9075y. URL: http: / / www . springerlink. com / content / g76w4717271w3556 / abstract/ (visited on 04/05/2012).

Wherton, Joseph P. and Andrew F. Monk (2008). “Technological opportunities for supporting people with dementia who are living at home". In: International Journal 
of Human-Computer Studies 66 (8), pp. 571-586. ISSN: 10715819. DOI: 10.1016 / j.ijhcs.2008.03.001. URL: http: / / linkinghub. elsevier. com / retrieve/pii/S1 071581908000268 (visited on 04/05/2012).

Wright, David (2011). "A framework for the ethical impact assessment of information technology". In: Ethics and Information Technology 13 (3), pp. 199-226. ISSN: 1388-1957. DOI: 10 . 1007 / s10676-010-9242-6. URL: http: / / wWw . springerlink . com/content/a6g05r6331224448/abstract/ (visited on 06/01/2012).

Wright, David and Kush Wadhwa (2010). "Mainstreaming the e-excluded in Europe: strategies, good practices and some ethical issues". In: Ethics and Information Technology 12 (2), pp. 139-156. ISSN: 1388-1957. DOI: 10 . 1007 / s10676-009-9213y. URL: http: / / www . springerlink. com/ content/f68n81326162r254 / abstract/ (visited on 04/05/2012).

Zaad, Lambert and Somaya Ben Allouch (2008). "The Influence of Control on the Acceptance of Ambient Intelligence by Elderly People: An Explorative Study". In: Ambient Intelligence. Ed. by Emile Aarts et al. In collab. with Emile Aarts et al. Vol. 5355. Lecture Notes in Computer Science. Springer Berlin / Heidelberg, pp. 58-74. ISBN: 978-3-540-89616-6. DOI: 10 . 1007 / 978-3-540-89617-3_ 5. URL: http: / / www . springerlink. com / content/u0g2165611127358/ abstract / (visited on 03/19/2012).

Zwijsen, Sandra A., Alistair R. Niemeijer, and Cees M.P.M. Hertogh (2010). “Ethics of using assistive technology in the care for community-dwelling elderly people: An overview of the literature". In: Aging \& Mental Health 15.4, pp. 419-427. DOI: $10.1080 / 13607863.2010 .543662$. URL: http: / / www. tandfonline.com/ doi/pdf/10.1080/13607863.2010.543662. 